\title{
Inhibition of HIV-1 infection in humanized mice and metabolic stability of protein phosphatase-1-targeting small molecule 1E7-03
}

\author{
Xionghao Lin ${ }^{1}$, Namita Kumari ${ }^{1}$, Catherine DeMarino ${ }^{6}$, Yasemin Saygideğer Kont ${ }^{5}$, \\ Tatiana Ammosova ${ }^{1,2,8}$, Amol Kulkarni ${ }^{4}$, Marina Jerebtsova ${ }^{3}$, Guelaguetza Vazquez- \\ Meves $^{1}$, Andrey Ivanov ${ }^{1}$, Dmytro Kovalskyy ${ }^{7}$, Aykut Üren ${ }^{5}$, Fatah Kashanchi ${ }^{6}$ and \\ Sergei Nekhai ${ }^{1,2,3}$ \\ ${ }^{1}$ Center for Sickle Cell Disease, College of Medicine, Howard University, Washington, DC, USA \\ ${ }^{2}$ Department of Medicine, College of Medicine, Howard University, Washington, DC, USA \\ ${ }^{3}$ Department of Microbiology, College of Medicine, Howard University, Washington, DC, USA \\ ${ }^{4}$ Department of Pharmaceutical Sciences, College of Pharmacy, Howard University, Washington, DC, USA \\ ${ }^{5}$ Lombardi Comprehensive Cancer Center, Georgetown University, Washington, DC, USA \\ ${ }^{6}$ Laboratory of Molecular Virology, George Mason University, Manassas, VA, USA \\ ${ }^{7}$ Department of Biochemistry, University of Texas Health Science Center, San Antonio, TX, USA \\ ${ }^{8}$ Yakut Science Center for Complex Medical Problems, Yakutsk, Russia \\ Correspondence to: Sergei Nekhai, email: snekhai@howard.edu \\ Keywords: HIV-1, protein phosphatase-1, small molecule HIV-1 inhibitor, HIV-1 infected humanized mice, metabolic stability \\ Received: March 22, 2017 \\ Accepted: July 14, 2017 \\ Published: August 07, 2017 \\ Copyright: Lin et al. This is an open-access article distributed under the terms of the Creative Commons Attribution License 3.0 \\ (CC BY 3.0), which permits unrestricted use, distribution, and reproduction in any medium, provided the original author and source \\ are credited.
}

\section{ABSTRACT}

We recently identified the protein phosphatase-1 - targeting compound, 1E7-03 which inhibited HIV-1 in vitro. Here, we investigated the effect of 1E7-03 on HIV-1 infection in vivo by analyzing its metabolic stability and antiviral activity of 1E7-03 and its metabolites in HIV-1 infected NSG-humanized mice. 1E7-03 was degraded in serum and formed two major degradation products, DP1 and DP3, which bound protein phosphatase-1 in vitro. However, their anti-viral activities were significantly reduced due to inefficient cell permeability. In cultured cells, 1E7-03 reduced expression of several protein phosphatase-1 regulatory subunits including Sds22 as determined by a label free quantitative proteomics analysis. In HIV-1-infected humanized mice, 1E7-03 significantly reduced plasma HIV-1 RNA levels, similar to the previously described HIV-1 transcription inhibitor F07\#13. We synthesized a DP1 analog, DP1-07 with a truncated side chain, which showed improved cell permeability and longer pharmacokinetic retention in mice. But DP1-07 was less efficient than 1E7-03 as a HIV-1 inhibitor both in vitro and in vivo, indicating that the full side chain of 1E7-03 was essential for its anti-HIV activity. Analysis of 1E7-03 stability in plasma and liver microsomes showed that the compound was stable in human, primate and ferret plasma but not in rodent plasma. However, 1E7-03 was not stable in human liver microsomes. Our findings suggest that 1E703 is a good candidate for future development of HIV-1 transcription inhibitors. Further structural modification and advanced formulations are needed to improve its metabolic stability and enhance its antiviral activity in non-human primate animals and humans. 


\section{INTRODUCTION}

The eradication of Human Immunodeficiency Virus (HIV)-1 infection is challenging because of the HIV-1 integration and establishment of a latent infection. While selective combination anti-retroviral therapy (cART) efficiently suppresses ongoing HIV-1 replication, latent HIV-1 infection in stable reservoirs such as resting CD4+ T cells, naive T cells and CD34 $4^{+}$ multipotent hematopoietic stem cells is not affected by the current antiretroviral drugs $[1,2]$. Also, cART does not target HIV-1 transcription which is activated during viral reactivation in latent reservoirs. Therefore, targeting HIV-1 transcription with a novel anti-HIV drug may help in preventing HIV-1 reactivation and facilitate permanent HIV-1 suppression.

We had previously developed small molecule inhibitors of HIV-1 transcription that target host protein phosphatase-1 (PP1) [3, 4]. Our previous studies showed that HIV-1 Tat interaction with PP1 is critical for the HIV-1 transcription activation [5-7]. The initial hit compound, $1 \mathrm{H} 4$, and its cyclopentan quinoline derivative with improved activity, 1E7-03, bind noncompetitively to PP1 in vitro without affecting PP1 enzymatic activity and prevent the interaction of HIV-1 Tat protein with PP1 $[3,4]$. PP1 is dimer of a catalytic subunit (PP $1 \alpha, \mathrm{PP} 1 \beta / \delta$ or PP $1 \gamma)$ and a regulatory subunit that targets PP1 holoenzyme into the specific cellular location and determines its activity and substrate specificity [8]. The interaction between PP1 catalytic and regulatory subunits occurs through a combination of short binding motifs, including an RVxF motif that is present in the majority of PP1 regulatory subunits [9]. The initial $1 \mathrm{H} 4$ compound was selected from a library of small molecules designed to bind to the PP1 RVxF binding site [4]. The 1E7-03 compound was selected from a library of $1 \mathrm{H} 4$ homologues which were also designed to fit PP1 RVxF binding cavity [3]. We recently showed that in addition to HIV-1, 1E7-03 also inhibited Ebola virus [10] and Rift valley fever virus [11] in infected cell cultures. While in vitro studies have yielded valuable information on the antiviral activity of 1E7-03 in cell cultures, the effect of 1E7-03 in vivo has not been explored. Thus, in the current study, we tested 1E7-03 metabolic stability and pharmacokinetics and analyzed its anti-HIV activity in vivo.

We first analyzed 1E7-03 stability in mouse plasma in vitro and its pharmacokinetics in mice. The stability of 1E7-03 in cell culture media and buffers with different $\mathrm{pH}$ was also analyzed. We generated a comprehensive profile of 1E7-03 degradation products (DPs) using a combination of LC/FT-MS/MS analysis with full (FL), neutral loss (NL) and multiple reaction monitoring (MRM) scans. Two major identified DPs, DP1 and DP3, were synthesized (Supplementary Figure 1), and tested for HIV-1 inhibition in cell culture. Their binding affinity to PP1 in vitro was tested using surface plasmon resonance technique. The effects on HIV-1 transcription and gene expression were also evaluated and compared with those of 1E7-03. We also tested cellular permeability of 1E7-03, DP1 and DP3. To understand the effect of 1E7-03 on PP1 in cultured cells, we performed label free quantitative proteomics analysis of HIV-1 infected CEM T cells treated with 1E7-03 versus untreated control. To determine the anti-HIV efficacy of 1E7-03 in vivo, we employed humanized NSG-BLT mice infected with the dual tropic HIV-1 89.6 virus [12]. For a comparison, we used the F07\#13 compound, a Tat peptide mimetic inhibitor that was previously shown to inhibit HIV-1 in this mouse model [13]. We generated an analog of DP1, DP1-07 and tested its activity in vivo. The identified labile sites of 1E703 and species variations in plasma and liver enzymes prompted us to further test its stability in plasma obtained from guinea pig, ferret, monkey and human, and liver microsomes from mouse and human. To our knowledge, this is the first in vivo study conducted on a cyclopentan quinoline based compound.

\section{RESULTS}

\section{Pharmacokinetics of 1E7-03 in mice and its degradation kinetics in mouse plasma}

To analyze the metabolism of 1E7-03 in vivo, we performed pharmacokinetics (PK) in mice for 1E7-03. The compound was injected intraperitonealy (i.p.) and the time-dependent plasma concentrations of 1E7-03 and its major metabolites, DP1 and DP3 were measured (Figure 1A and 1B, see details for metabolites identification in Supplementary Materials, Supplementary Figures 2-7; Supplementary Tables 1 and 2). The main plasma pharmacokinetic parameters of 1E7-03 and its main metabolites are summarized in Table 1. The $T_{\max }, C_{\max } t_{1 / 2}$ and $A U C_{\text {last }}$ for 1E7-03 were found to be $0.5 \mathrm{hr}, 3.43 \mu \mathrm{M}, 3.39 \mathrm{hr}$ and $12.22 \mu \mathrm{M} \cdot \mathrm{hr}$ (Table 1). DP1 was accumulated with maximum at $3 \mathrm{hrs}$ post injection (Figure 1B). To analyze 1E7-03 stability in mouse plasma, we incubated $10 \mu \mathrm{M} 1 \mathrm{E} 7-03$ in the plasma at $37^{\circ} \mathrm{C}$ for $24 \mathrm{hrs}$. Samples were collected at different times, 1E7-03 and its DPs were extracted and quantified by LC/FT-MS analysis (see details for LC/FTMS instrument and method validation in Supplemental Materials; Supplementary Figure 8 and Supplementary Tables 3-5). 1E7-03 degradation kinetics in plasma paralleled that in mice (Figure 1B-1D). The degradation dynamic plot showed that $40 \%$ of $1 \mathrm{E} 7-03$ had degraded after 2 hrs incubation and over $85 \%$ of 1 E7-03 had degraded after 4 hrs of incubation (Figure 1C). The DP1 levels progressively increased with the degradation of 1E7-03 and reached their maximum at $2 \mathrm{hrs}$ (Figure 1D). In contrast, DP3 was present at low levels, suggesting that DP1 remained the major degradation product. Thus, the 1E7-03 was not stable in mice and mouse plasma 
A
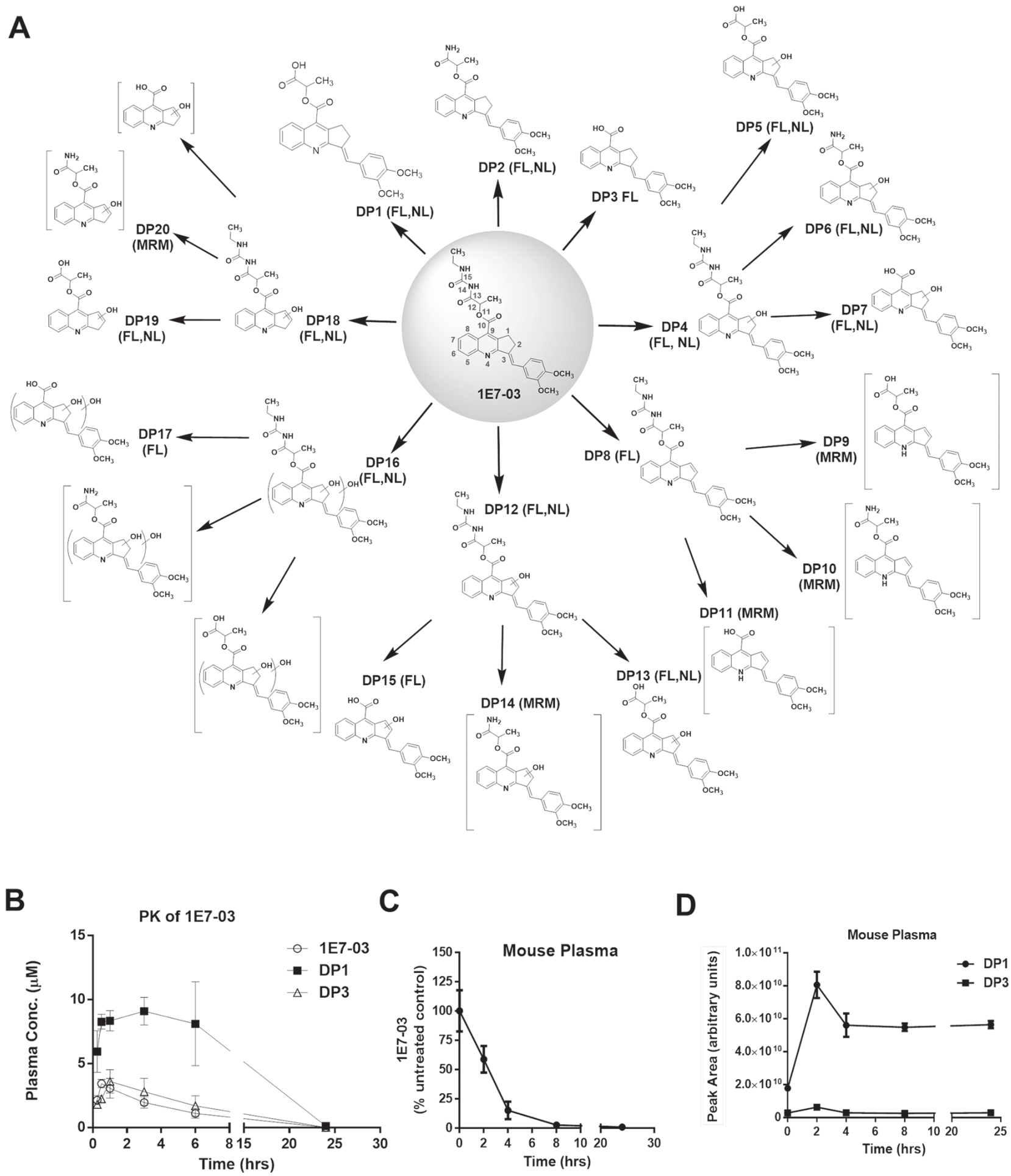

Figure 1: Degradation products of 1E7-03, pharmacokinetic of 1E7-03 in mice and its degradation kinetic in mouse plasma. (A) All possible 1E7-03 degradation products (DPs) were identified when 1E7-03 was incubated under different experimental conditions, including mouse plasma $(24 \mathrm{hrs})$ and buffers with $\mathrm{pH} 4, \mathrm{pH} 7$ and $\mathrm{pH} 10(48 \mathrm{hrs})$ at $37^{\circ} \mathrm{C}$. Small molecules were extracted with cold acetone precipitation and identified by LC/FT-MS analysis that included FL, NL and MRM scans as indicated on the figure. A total of 20 DPs are shown. Brackets indicate trace DPs that were only detected by MRM. Major DPs of 1E7-03 detected in mouse plasma were DP1, DP3, and followed by DP2 which was present at a very low level. (B) Pharmacokinetics of 1E7-03 in mice. Mice were injected i.p. with $30 \mathrm{mg} / \mathrm{kg}$ of 1E7-03. The concentrations of 1E7-03 and its major DPs were quantified by LC/FT-MS in the plasma at several time points for up to $24 \mathrm{hrs}$. Three mice were used for each time point. The means \pm SD are shown. (C-D) Degradation kinetic of 1E7-03 in mouse plasma (C) and dynamic changes of the major DPs DP1 and DP3 (D). 1E7-03 $(10 \mu \mathrm{M})$ was added to mouse plasma and incubated at $37^{\circ} \mathrm{C}$ for $24 \mathrm{hrs}$. Samples were collected at different time points, 1E7-03 and its DPs were extracted and quantified by LC/FT-MS analysis. 
Table 1: Pharmacokinetic parameters following intraperitoneal (i.p.) administration of compounds 1E7-03 and DP1-07 (mean, n=3)

\begin{tabular}{lcccccc}
\hline Compounds & Dose $(\mathbf{m g} / \mathbf{k g})$ & $\boldsymbol{C}_{\max }(\boldsymbol{\mu M})$ & $\boldsymbol{T}_{\max }(\mathbf{h r})$ & $\boldsymbol{A U \boldsymbol { C } _ { \text { last } }}(\mathbf{h r} \boldsymbol{\mu M})$ & $\boldsymbol{t}_{\mathbf{1 / 2}}(\mathbf{h r})$ & $\boldsymbol{M R T}_{\text {last }}(\mathbf{h r})$ \\
\hline 1E7-03 & 30 & 3.43 & 0.5 & 12.22 & 3.39 & 2.40 \\
DP1 & - & 9.09 & 3.0 & 123.97 & 3.20 & 4.98 \\
DP3 & - & 3.61 & 1.0 & 30.66 & 2.44 & 4.39 \\
DP1-07 & 100 & 42.71 & 6.0 & 705.61 & 14.29 & 10.68 \\
DP1-07P1 & - & 7.54 & 6.0 & 123.94 & 13.45 & 10.50 \\
DP1-07P2 $^{*}$ & - & 23.71 & 6.0 & 288.38 & 4.66 & 8.86 \\
\hline
\end{tabular}

Pharmacokinetic parameters were calculated by non-compartmental modeling using WinNonlin.

$C_{\text {max }}$, peak plasma concentration; $T_{\text {max }}$, time to peak plasma concentration; $A U C_{\text {last }}$, area under the concentration vs. time curve from $0 \mathrm{hr}$ up to the quantification time; $t_{1 / 2}$, elimination half-life; $M R T_{\text {last }}$, mean resident time from $0 \mathrm{hr}$ to the last detectable point. ${ }^{*}$ The concentrations of compounds DP1-07P1 and DP1-07P2 in plasma were calculated by calibration curves of DP1 and DP3 due to lack of standards.

and its degradation was likely due to the hydrolysis of the amide bond $\mathrm{C}_{13}-\mathrm{N}_{14}$ (see central panel in Figure 1A).

To identify additional 1E7-03 degradation products, 1E7-03 was subjected to various conditions, including incubation in buffers with $\mathrm{pH} 4, \mathrm{pH} 7$ and $\mathrm{pH} 10$ for 48 hrs at $37^{\circ} \mathrm{C}$. All available DPs were identified by advanced LC/FT-MS/MS analysis that included FL, NL and MRM scans. A total of 20 DPs were identified (Figure 1A and Table 2 ; see also Supplementary Figures 2-5). Of these 20 DPs, 15 DPs were identified by FL scan, 11 DPs were detected by NL scan, and 5 DPs were present at trace amounts and could only be detected by MRM scans. The amide bonds $\mathrm{C}_{13}-\mathrm{N}_{14}$ and $\mathrm{N}_{14}-\mathrm{C}_{15}$, the ester bond $\mathrm{C}_{10}-\mathrm{O}_{11}$, and $\mathrm{C}_{1} / \mathrm{C}_{2}, \mathrm{C}_{3}$ on cyclopentene ring (Figure 1A) were identified as labile sites or "hotspots".

\section{E7-03 stability in cell culture}

In our previous studies, 1E7-03 was used to treat cultured cells infected with HIV-1 [3, 4]. To test the stability of 1E7-03 in cell culture media, the compound was incubated in the complete media for $48 \mathrm{hrs}$ at $37^{\circ} \mathrm{C}$ and aliquots were collected at different time points. During the incubation, 1E7-03 remained stable and did not undergo degradation (Figure 2A). In contrast, 1E703 incubated in serum free media underwent degradation with only $7 \%$ of the compound remaining after $24 \mathrm{hrs}$ of incubation at $37^{\circ} \mathrm{C}$ (Figure 2B). The major degradation product in serum free media was DP3 $(91.98 \%$, Figure 2B). As 1E7-03 remained largely intact in complete media (98.6\% remaining, Figure 2B), serum albumin may have a protective effect against 1E7-03 degradation. To test this possibility, 1E7-03 was incubated in phosphate buffered saline (PBS) with and without the addition of $10 \%$ bovine serum albumin (Figure 2C). 1E7-03 underwent quick degradation in PBS with over $80 \%$ of the compound degraded after $4 \mathrm{hrs}$ of incubation (Figure 2C). An addition of $10 \%$ BSA stabilized 1 E7-03 with $75 \%$ of the compound remaining intact after $4 \mathrm{hrs}$ of incubation and over $50 \%$ remaining after $24 \mathrm{hrs}$ of incubation (Figure 2C). Thus albumin present in culture media might prevent 1E7-03 from being degraded. We also tested the activity of 1E7-03 after incubation in complete media in a single round HIV-1 infection assay in CEM T cells infected with VSVg-pseudotyped HIV-1 virus expressing luciferase (HIV-1-LUC-G) (Figure 2D). The untreated 1E7-03 and the compound incubated in complete media for $24 \mathrm{hrs}$ inhibited HIV-1 to the same extent (Figure 2D) suggesting that 1E7-03 continued to be active after incubation in complete media.

\section{Binding of 1E7-03, DP1 and DP3 to PP1 in vitro}

To determine whether the major degradation products of 1E7-03 retained the ability to bind PP1, we analyzed their binding of PP1 in vitro. Recombinant PP1 protein was purified as previously described [3] (see purification details in Materials and Methods) and used to analyze the binding of 1E7-03 and chemically synthesized DP1 and DP3 with surface plasmon resonance technology on a Biacore T-200 instrument (Figure 3A). The PP1 was immobilized on a sensor chip CM5 and different concentrations of 1E7-03, DP1 and DP3 were injected over the surface of the chip. Direct binding of the compounds to PP1 was measured in real time and binding affinities were calculated based on a 1:1 binding model. 1E7-03, DP1 and DP3 bound to PP1 with similar low micromolar $\mathrm{K}_{\mathrm{D}}$ values (Figure $3 \mathrm{~B}$ ). A control PP1 binding peptide containing a retinoblastoma protein-derived phosphopeptide linked to an $\mathrm{RVxF}$ containing sequence derived from HIV-1 Tat [3] (pRb-Tat) 
showed a 20-40 times higher binding ability $\left(\mathrm{K}_{\mathrm{D}}=0.15 \times 10^{-6}\right.$, Figure 3B). A mutant pRb-Tat peptide with QACA mutation in the RVxF motif did not bind to PP1 in accord with our previous report [4] (Figure 3B). This result shows that the DPs retained the ability to interact with PP1 in vitro.

To determine whether the compounds bound to the RVxF-binding site, a competition assay was performed with the compounds and pRb-Tat peptide previously shown to occupy RVxF-binding on PP1 (Figure 3C). Increasing concentrations of $\mathrm{pRb}$-Tat peptide $(10 \mathrm{nM}$, $25 \mathrm{nM}, 50 \mathrm{nM}, 75 \mathrm{nM}$ and $100 \mathrm{nM}$ ) were added to the compounds that were kept at a constant concentration (1 $\mu \mathrm{M}$ ) (Figure 3C). DMSO was used as a vehicle control. All three compounds competed with the $\mathrm{pRb}$-Tat protein for binding to PP1 with DP1 being the best competitor as compared to 1E7-03 or DP3. Thus, Biacore experiments demonstrated a direct binding of 1E7-03 degradation products, DP1 and DP3, to PP1 and a competition with the PP1-binding peptide containing an RVxF motif. DP1 showed a slightly better binding to PP1 in vitro and superior competition capability when used at low concentration in comparison to 1E7-03 or DP3.

\section{Anti-HIV-1 activity of 1E7-03 degradation products}

To analyze whether DP1 and DP3 retained the ability to inhibit HIV-1 in vitro, we analyzed HIV-1 inhibition in CEM T cells infected with HIV-1-LUC-G. While 1E7-03 effectively inhibited HIV-1 $\left(\mathrm{IC}_{50}=1.7 \mu \mathrm{M}\right)$, DP1 was 10 times less effective $\left(\mathrm{IC}_{50}=17 \mu \mathrm{M}\right)$ and DP3 was not inhibitory $\left(\mathrm{IC}_{50}>180 \mu \mathrm{M}\right)$ (Figure 4A). DP1 and DP3 had no effect on cell viability, whereas 1E7-03 showed about $30 \%$ viability reduction at the highest tested $180 \mu \mathrm{M}$ concentration (Figure 4B).

Next, we analyzed the effect of 1E7-03, DP1 and DP3 on purified luciferase activity in vitro. While 1E703 had no effect on luciferase activity at concentrations below $100 \mu \mathrm{M}$, both DP1 and DP3 showed potent luciferase inhibition at $\mathrm{IC}_{50}=37 \mu \mathrm{M}$ and $\mathrm{IC}_{50}=7.2 \mu \mathrm{M}$, correspondingly (Figure 4C). Thus, the effect of DP1 and DP3 on HIV-1-LUC-G could be due to the inhibition of luciferase and not due to the viral inhibition.

To further analyze whether DP1 and DP3 can inhibit HIV-1, we measured HIV-1 mRNA expression in CEM T cells infected with HIV-1-LUC-G. The expression of HIV1 env mRNA (Figure 4D) and gag mRNA (Figure 4E) was significantly reduced in the cell treated with $10 \mu \mathrm{M}$ 1E7-03. In contrast HIV-1 env and gag mRNA expression was not affected when DP1 and DP3 were used at $10 \mu \mathrm{M}$ concentrations (Figure 4D and 4E). DMSO treatment slightly induced env expression in accord with previous observations $[14,15]$. We observed strong inhibition of env and gag expression when $5 \mu \mathrm{M}$ azidothymidine (AZT) or $5 \mu \mathrm{M}$ lamivudine (3TC) were used (Figure 4D and 4C).
We next tested the effect of 1E7-03 on HIV-1 integration which did not show any significant effect (Figure $4 \mathrm{~F}, p=0.97$ for DMSO versus 1E7-03). To exclude the "off target" effect of 1E7-03, we also tested the effect of 1E7-03 on expression of cellular genes. We observed slight induction of RSP13 mRNA and $\beta$-actin mRNA (Figure 4G), suggesting that 1E7-03 did not inhibit cellular transcription.

Finally, we analyzed whether the reduced HIV-1 inhibitory activities of DP1 and DP3 were due to their inefficient cellular permeability. CEM T cells were incubated with $10 \mu \mathrm{M} 1 \mathrm{E} 7-03, \mathrm{DP} 1$ or DP3 for $24 \mathrm{hrs}$ at $37^{\circ} \mathrm{C}$. The compounds remaining in media and taken up by the cells were quantified by LC/FT-MS in media aliquots and cell lysates. 1E7-03, DP1 and DP3 were all detected in media (Figure 4H). While 1E7-03 showed good cell permeability with $3 \%$ accumulation in cellular lysates (Figure 4H), DP1 accumulation in the cell lysate was less than $0.2 \%$ (Figure $4 \mathrm{H}$ ) and DP3 was not detected in lysates (Figure 4H). Thus cells accumulated DP1 more than 10 times less efficiently than 1E7-03 which may explain its lower activity against HIV-1. The lack of cellular penetration by DP3 also explains its inability to inhibit HIV-1.

\section{Effect of 1E7-03 on cellular proteome}

We recently showed that PP1-activating small molecule SMAPP1 induced expression of PP1-regulatory Sds22 subunit in CEM T cells [16]. To determine if 1E7-03 has a global effect on protein expression and specifically on PP1 and its regulatory subunits, we analyzed the proteins expressed in 1E7-03-treated CEM T cells using nano liquid chromatography followed by FTMS/MS tandem mass spectrometry [16]. We performed a short-gun label free quantitative proteomics analysis on whole cell extracts of 1E7-03-treated CEM T cells. A total of 3606 peptides derived from 796 proteins were identified by Proteome Discoverer 1.4 (Figure 5A). To determine whether the levels of PP1-related proteins were affected by 1E7-03 treatment, we quantified protein expression using a label-free approach. For this purpose, we used SIEVE 2.1 software which allows for the extraction of selected ions and their quantification by integrating their ion elution profiles (Figure 5B). Over 140 proteins were affected by 1E7-03. We used Ingenuity Pathway Analysis (IPA) software to identify a network of PP1-related proteins (Figure 5C). Four PP1 regulatory subunits were downregulated by 1E7-03, including Sds22 subunit encoded by PPP1R7 gene (Figure 5D). Sds22 was identified by the MS/MS analysis of its representative peptides (Figure 5E), and its quantification by SIEVE showed down regulation (Ratio $_{1 \mathrm{E} 7-03 / \text { Control }}=0.804, p=0.024$, Figure 5F) compared to $\alpha$-tubulin $\left(\right.$ Ratio $_{1 \mathrm{E} 7-03 / \mathrm{Control}}=0.936$, $p=0.67$, Figure 5F). Thus, PP1-related proteins might be affected by 1E7-03 treatment and contribute to the HIV-1 resistance. 
Table 2: Degradation products (DPs) of 1E7-03 characterized by LC/FT-MS after incubated in buffers ${ }^{\text {a }}$ and mouse plasma $^{\text {b }}$ at $37^{\circ} \mathrm{C}$

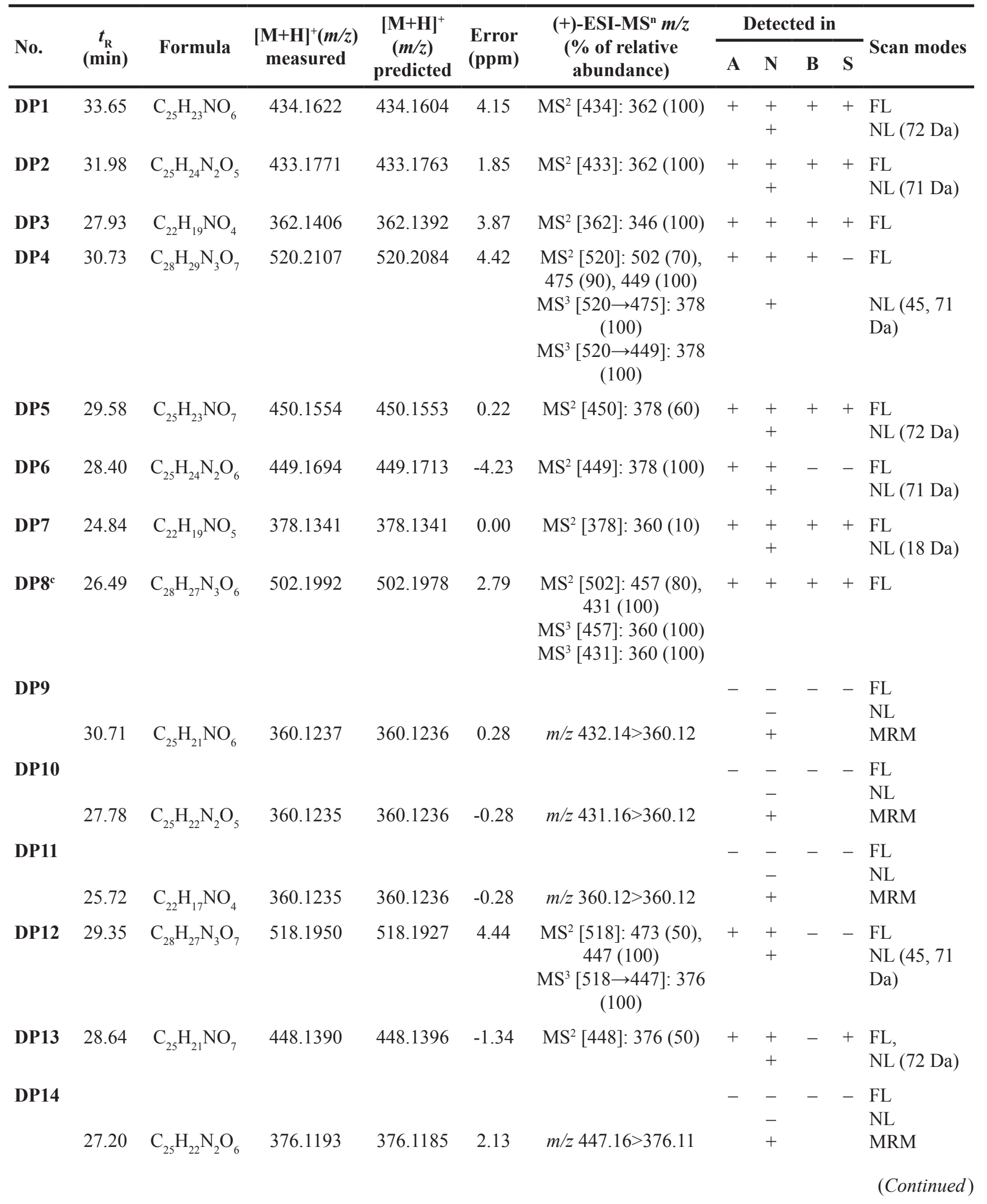




\begin{tabular}{|c|c|c|c|c|c|c|c|c|c|c|c|}
\hline \multirow{2}{*}{ No. } & \multirow{2}{*}{$\begin{array}{c}t_{\mathrm{R}} \\
(\min )\end{array}$} & \multirow{2}{*}{ Formula } & \multirow{2}{*}{$\begin{array}{c}{[\mathbf{M}+\mathbf{H}]^{+}(m / z)} \\
\text { measured }\end{array}$} & \multirow{2}{*}{$\begin{array}{c}{[\mathrm{M}+\mathrm{H}]^{+}} \\
(\mathrm{m} / \mathrm{z}) \\
\text { predicted }\end{array}$} & \multirow{2}{*}{$\begin{array}{l}\text { Error } \\
(\mathrm{ppm})\end{array}$} & \multirow{2}{*}{$\begin{array}{c}(+) \text {-ESI-MS }{ }^{\mathrm{n}} \boldsymbol{m} / \mathbf{z} \\
\text { (\% of relative } \\
\text { abundance) }\end{array}$} & \multicolumn{4}{|c|}{ Detected in } & \multirow{2}{*}{ Scan modes } \\
\hline & & & & & & & $\mathbf{A}$ & $\mathbf{N}$ & B & $\mathbf{S}$ & \\
\hline DP15 & 27.13 & $\mathrm{C}_{22} \mathrm{H}_{17} \mathrm{NO}_{5}$ & 376.1198 & 376.1185 & 3.46 & $\mathrm{MS}^{2}[376]: 358(20)$ & + & + & + & - & FL \\
\hline DP16 & 29.35 & $\mathrm{C}_{28} \mathrm{H}_{29} \mathrm{~N}_{3} \mathrm{O}_{8}$ & 536.2057 & 536.2033 & 4.48 & $\operatorname{MS}^{2}$ [536]: 491 & + & $\begin{array}{l}+ \\
+\end{array}$ & - & - & $\begin{array}{l}\text { FL } \\
\text { NL (45 Da) }\end{array}$ \\
\hline DP17 & 28.07 & $\mathrm{C}_{20} \mathrm{H}_{19} \mathrm{NO}_{6}$ & 394.1308 & 394.1291 & 4.31 & $\begin{array}{c}\mathrm{MS}^{2}[394]: 376(100), \\
332(50)\end{array}$ & - & + & + & - & FL \\
\hline DP18 & 29.33 & $\mathrm{C}_{19} \mathrm{H}_{19} \mathrm{~N}_{3} \mathrm{O}_{5}$ & 370.1421 & 370.1430 & -2.43 & $\begin{array}{c}\mathrm{MS}^{2}[370]: 325(45) \\
299(60), 228(100)\end{array}$ & + & $\begin{array}{l}+ \\
+\end{array}$ & - & - & $\begin{array}{l}\text { FL } \\
\text { NL }(45,71 \\
\mathrm{Da})\end{array}$ \\
\hline \multirow[t]{2}{*}{ DP19 } & 28.62 & $\mathrm{C}_{16} \mathrm{H}_{13} \mathrm{~N}_{1} \mathrm{O}_{5}$ & 300.0872 & 300.0872 & 0.00 & $\mathrm{MS}^{2}$ [300]: $228(100)$ & - & $\begin{array}{l}- \\
+\end{array}$ & - & + & $\begin{array}{l}\text { FL } \\
\text { NL (72 Da) }\end{array}$ \\
\hline & 28.62 & & 228.0659 & 228.0661 & -0.88 & $\mathrm{~m} / \mathrm{z} 300.09>228.06$ & & + & & & MRM \\
\hline DP20 & 29.27 & $\mathrm{C}_{16} \mathrm{H}_{14} \mathrm{~N}_{2} \mathrm{O}_{4}$ & 228.0656 & 228.0661 & -2.19 & $\mathrm{~m} / \mathrm{z} 299.10>228.06$ & - & $\begin{array}{l}- \\
- \\
+\end{array}$ & - & - & $\begin{array}{l}\text { FL } \\
\text { NL } \\
\text { MRM }\end{array}$ \\
\hline
\end{tabular}

FL: Full scan ( $m / z$ 200-1500); NL: neutral loss scan; MRM: multiple reaction monitoring scan; A: pH=4; N: $\mathrm{pH}=7$; B: $\mathrm{pH}=10$; ${ }^{\mathrm{a}} 1 \mathrm{E} 7-03$ was incubated in the buffers with different $\mathrm{pH}$ for up to $48 \mathrm{hrs} .{ }^{\mathrm{b}} 1 \mathrm{E} 7-03$ was incubated in the mouse plasma up to $24 \mathrm{hrs} .{ }^{\mathrm{C}} \mathbf{D P 8}$ was detected in the buffers after $24 \mathrm{hrs}$ incubation.

\section{Antiviral efficacy of 1E7-03 in NSG mice with established HIV-1 infection}

Next, we determined the effect of 1E7-03 on HIV1 infection in vivo using NSG mice infected with the dual tropic HIV-1 89.6. Groups of 3 mice were treated with a single i.p. of $1 \mathrm{E} 7-03(3 \mathrm{mg} / \mathrm{kg})$ or F07\#13 (1.5 $\mathrm{mg} / \mathrm{kg}$ ) at a time point when HIV-1 89.6 replication normally peaks in these animals [13]. 1E7-03 reduced HIV TAR RNA by $>40$-fold, $p=0.0001$ (from a mean of $10^{5.19}$ HIV RNA copies per $100 \mu \mathrm{L}$ of blood in untreated mice to $10^{3.59}$ copies in 1E7-03 treated mice, Figure $6 \mathrm{~A}$ ) and TAR-gag RNA by $>39$-fold, $p=0.0014$ (from a mean of $10^{4.90}$ HIV TAR-gag RNA copies per $100 \mu \mathrm{L}$ of blood in untreated mice to $10^{3.31}$ copies in 1E7-03 treated mice, Figure 6B). In comparison, F07\#13 (a Tat mimetic inhibitor) at $1.5 \mathrm{mg} / \mathrm{kg}$ only reduced TAR RNA by $4.7-$ fold, $p=0.0117$ (from a mean of $10^{5.19}$ HIV TAR RNA copies per $100 \mu \mathrm{L}$ of blood in untreated mice to $10^{4.52}$ copies in F07\#13 treated mice, Figure 6A) and TAR-gag RNA by 4.6 -fold, $p=0.0110$ (from a mean of $10^{4.90} \mathrm{HIV}$ TAR-gag RNA copies per $100 \mu \mathrm{L}$ of blood in untreated mice to $10^{4.24}$ copies in F07\#13 treated mice, Figure 6B). These findings showed that despite its instability, 1E7-03 retained its anti-HIV-1 inhibitory activity in vivo which was comparable to and even exceeded the previously tested F07\#13 inhibitor.

\section{DP1-07, a DP1 analog with improved cell permeability and $P K$ properties}

To improve cellular permeability of DP1, we synthesized DP1-07 compound (see details in Materials and Methods; Supplementary Figure 1) and tested its cellular permeability. CEM T cells were incubated with $10 \mu \mathrm{M}$ DP1-07 for $24 \mathrm{hrs}$ at $37^{\circ} \mathrm{C}$. The amount of DP107 in media and its cellular uptake was quantified by LC-MS as described above. DP1-07 showed good cell permeability with $2.7 \%$ accumulation in the cellular lysate (Figure 7A), which was similar to the permeability of 1E7-03 compound. Next, we carried out PK of DP1-07 in the mice. The time-dependent plasma concentrations of DP1-07 and its pharmacokinetic parameters were shown in Figure 7B and Table 1. As expected, DP1-07 showed good stability and pharmacokinetic properties (Figure 7B). DP1-07 (18 $\mu \mathrm{M})$ was present after $24 \mathrm{hrs}$ post-injection in the collected murine blood (Figure 7B). Of note, we were able to inject a higher amount of DP107 because of its better solubility. DP1-07 reached the peak plasma concentration in mice at approximately 6 hrs $\left(T_{\max }\right)$ with a concentration $\left(C_{\max }\right)$ of $42.71 \mu \mathrm{M}$. The area under the plasma concentration-time curve $\left(A U C_{\text {last }}\right)$ was found to be $705.61 \mu \mathrm{M} \cdot \mathrm{hr}$ (Table 1). Using LC/FTMS analysis, we observed two major products of DP107 degradation, DP1-07P1 and DP1-07P2 (Figure 7B- 
7C). The plasma concentration of DP1-07P1 was low at each time points analyzed. DP1-07P2 accumulation paralleled DP1-07 kinetics pattern but its concentration was much lower than DP1-07 $\left(C_{\max }=23.71 \mu \mathrm{M}\right)$. Thus, DP1-07 compound exhibited improved cell permeability and $\mathrm{PK}$ properties over 1E7-03.

\section{HIV-1 inhibition by DP1-07 in vitro and in vivo}

To test the biological activity of DP1-07, we analyzed its effect on $\mathrm{HIV}-1$ replication in vitro and in vivo. DP1-07 was not efficient in the inhibition of single round HIV-1 replication in CEM T-cells infected with HIV-1-LUC-G (Figure 7D, $\mathrm{IC}_{50}>66 \mu \mathrm{M}$ ). It did not inhibit luciferase in vitro (Figure 7E). DP1-07 showed reduced toxicity in CEM T cells compared to 1E7-03 (Figure 7F). To determine if DP1-07 inhibits HIV-1 in vivo, single doses of DP1-07 at $3 \mathrm{mg} / \mathrm{kg}$ and $1.5 \mathrm{mg} / \mathrm{kg}$ were given to HIV-1 ${ }_{89.6}$ infected NSG mice by i.p. The F07\#13 (1.5 $\mathrm{mg} / \mathrm{kg}$ ) was used as a positive control. DP1-07 reduced HIV TAR RNA from a mean of $10^{6.8}$ copies to $10^{6.2}$ copies at $3 \mathrm{mg} / \mathrm{kg}$ (3.8-fold, $p=0.6617$, Figure $7 \mathrm{G})$ and to $10^{6.5}$ copies at $1.5 \mathrm{mg} / \mathrm{kg}(1.8$-fold, $p=0.7477$, Figure $7 \mathrm{G})$, while F07\#13 reduced HIV TAR RNA by 10.2 -fold, $p=0.0422$ (Figure 7G). Thus, DP-07 was not an efficient HIV-1 inhibitor in vitro and showed reduced efficiency in vivo compared to F07\#13 or 1E7-03, despite its improved cellular permeability and PK.
A

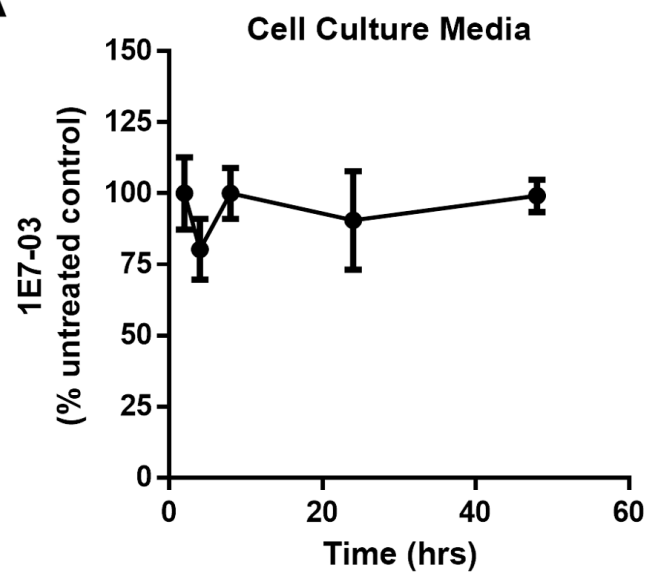

C

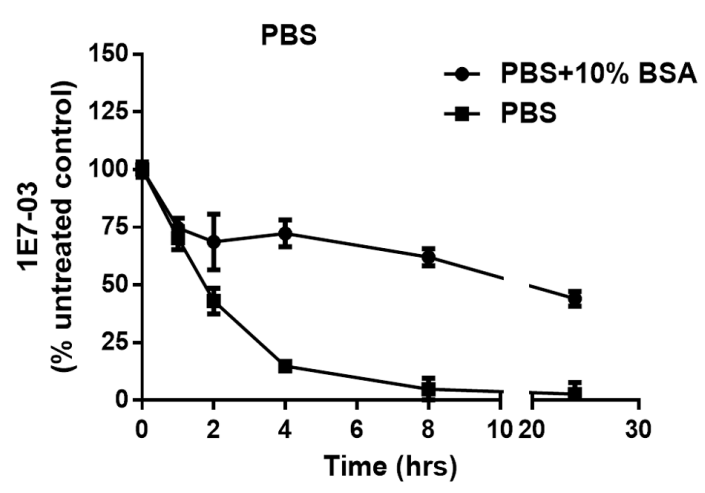

B

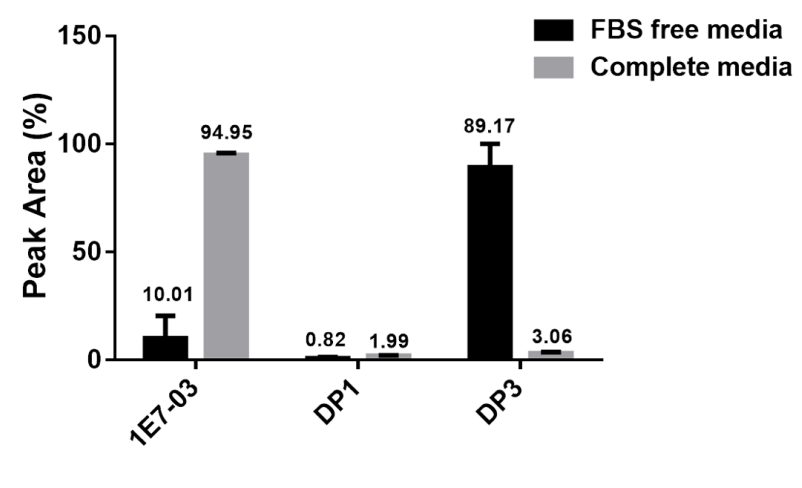

D

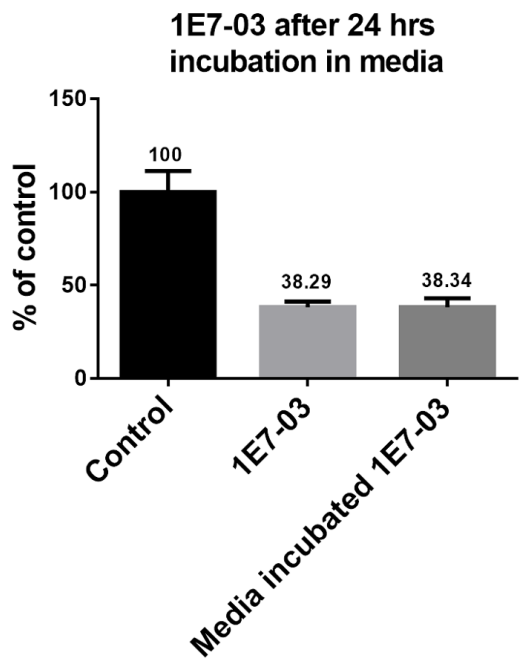

Figure 2: Stability of 1E7-03 in cell culture and the effect of media incubation on its anti-HIV-1 activity. (A) Stability of 1E7-03 in media supplemented with $10 \%$ fetal bovine serum (FBS). 1E7-03 $(10 \mu \mathrm{M})$ was added to the media and incubated at $37^{\circ} \mathrm{C}$ for $48 \mathrm{hrs}$. Samples were collected at different time points, 1E7-03 was extracted and quantified by LC/FT-MS analysis. (B) 1E7-03 and DPs degradation in FBS-free media and media supplemented by 10\% FBS (complete media). Results at 24 hrs of incubation are shown. (C) 1E7-03 degradation in PBS with and without 10\% bovine serum albumin (BSA). (D) The comparison of untreated 1E7-03 and 1E7-03 incubated in completed media for $24 \mathrm{hrs}$ on single round of HIV-1 replication. CEM T cells were infected with HIV-1-LUC-G and treated with control or media incubated 1E7-03. Percent of luciferase activity is shown. All results were shown by the means \pm SD. 


\section{Stability profiles of 1E7-03 in plasma and liver microsomes from various species}

Hydrolysis of compounds containing amides and esters by plasma enzymes [17] may vary in different species [18]. Thus we investigated the stability of 1E703 in plasma obtained from various species, including guinea pig, ferret, monkey and human (Figure 8A). For comparison, the corresponding plasma concentrationtime profile of 1E7-03 in mouse plasma was also shown (Figure 8A). 1E7-03 underwent quick degradation in guinea pig plasma similar to the mouse plasma with about $80 \%$ of the compound being degraded after $4 \mathrm{hrs}$ of incubation. In contrast, 1E7-03 remained relatively stable in human, monkey and ferret plasma with over $50 \%$ remaining even after $24 \mathrm{hrs}$ of incubation (Figure 8A). Liver microsomes represent a critical experimental model to estimate the drug metabolic fates in vivo [19]. We tested the stability of 1E7-03 in liver microsomes obtained from humans and mice. After 1 $\mathrm{hr}$ of incubation, 1E7-03 remained stable in mouse liver microsomes (91\% remaining, Figure $8 \mathrm{~B}$ ), while $39 \%$ of 1E7-03 in human liver microsomes was degraded and converted into DP1 (Figure 8B).
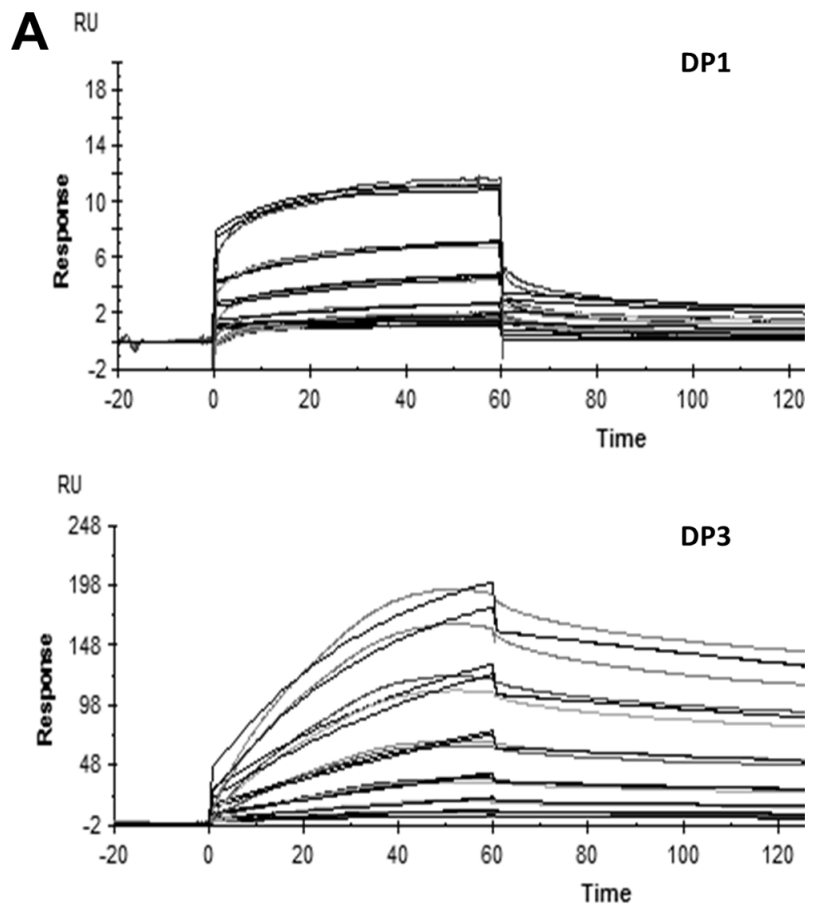

\section{DISCUSSION}

Prior to the first administration of a drug in humans, it is typically tested in small laboratory animals to determine its in vivo activity, drug pharmacokinetics and metabolic stability, all of which are critical in the selection of drug candidates [20]. Comprehensive analysis of in vivo activity and metabolic behavior can provide effective guidance for the further structure optimization of lead compounds and subsequent preclinical or clinical studies.

We first determined 1E7-03 stability both in vivo and in vitro. 1E7-03 rapidly degraded into its main metabolite DP1 with a $t_{1 / 2}$ of $3.39 \mathrm{hrs}$ when it was given to mice by a single dose i.p. Accompanied by the degradation of 1E703, DP1 level increased reaching $C_{\max }$ of $9.09 \mu \mathrm{M}$ after $3 \mathrm{hrs}$ of injection. This observation suggested that DP1 could potentially contribute to the in vivo anti-HIV activity of 1E7-03. The dynamic stability plot of 1E7-03 in mouse plasma showed a very similar profile with its PK profile. Thus hydrolysis in plasma is likely to be the major route for clearance of 1E7-03. Rapid DP1 formation indicates that the amide bond $\mathrm{C}_{13}-\mathrm{N}_{14}$ in 1E7-03 is a hotspot that is being cleaved in murine plasma. In contrast, 1E7-03 showed good stability in complete but not the serum-

\begin{tabular}{|c|c|}
\hline \multirow{2}{*}{$\begin{array}{l}\text { Small Molecule } \\
\text { Compounds }\end{array}$} & PP1 WT \\
\hline & $\mathrm{K}_{\mathrm{D}}(\mathrm{M})$ \\
\hline $1 \mathrm{E} 7-03$ & $6.16 \mathrm{E}-6$ \\
\hline DP1 (mw 433) & $3.75 \mathrm{E}-6$ \\
\hline DP3 (mw361) & $4.88 \mathrm{E}-6$ \\
\hline pRb-Tat & $0.155 \mathrm{E}-6$ \\
\hline pRb-Tat mutant & No binding \\
\hline
\end{tabular}
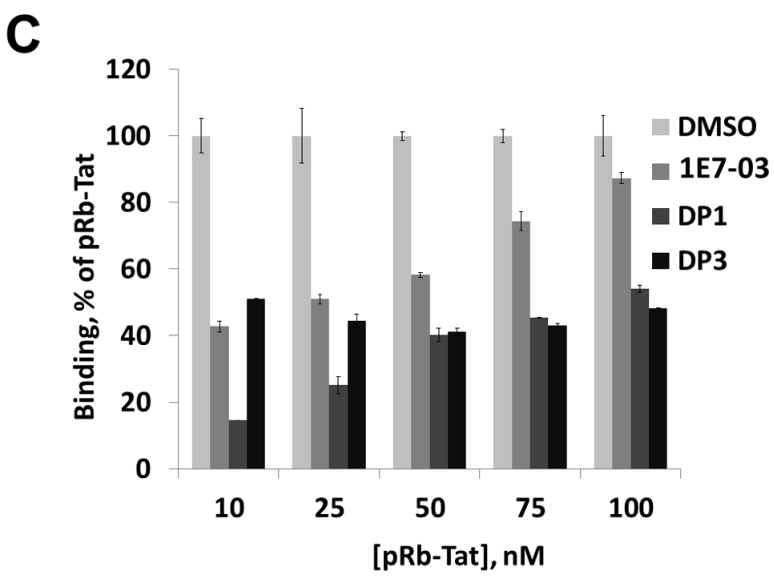

Figure 3: PP1 binding of 1E7-03, DP1 and DP3. Binding of 1E7-03, DP1 and DP3 to recombinant PP1 was measured by surface plasmon resonance. (A) Raw data showing binding of DP1 and DP3 to PP1 protein. X axis represents time in seconds and Y axis represents changes in total mass on microchip surface, which was expressed as resonance units. A positive deflection indicated binding of DP1 and DP3 to PP1 immobilized on a microchip surface. Each line represents a different concentration of DP1 and DP3 (0-40 $\mu$ M). Each concentration was run two times. (B) The equilibrium dissociation constants $\left(\mathrm{K}_{\mathrm{D}}\right)$ calculated based on a 1:1 binding model. (C) Binding competition assay. 1E7-03, DP1 and DP3 compete with pRb-Tat peptide for binding to PP1. Different concentrations of pRb-Tat hybrid peptide were premixed with $1 \mu \mathrm{M}$ of compounds. 
A

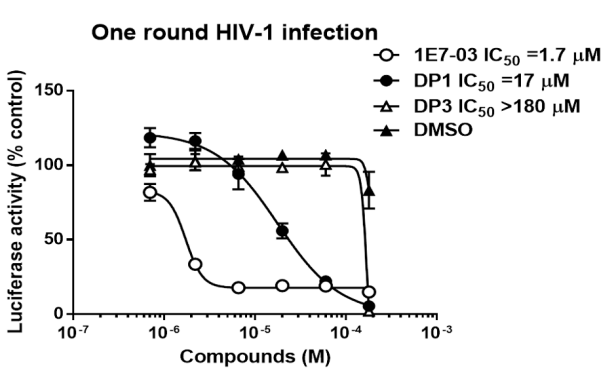

C

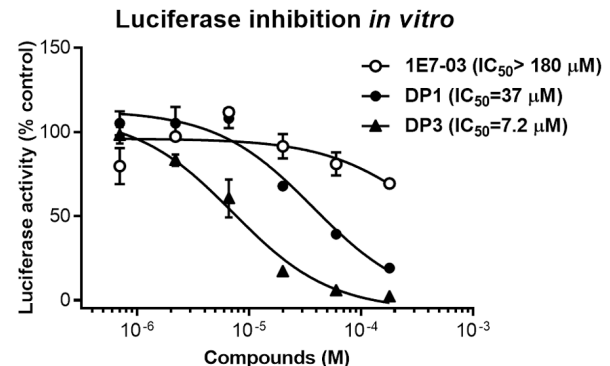

$\mathbf{E}$

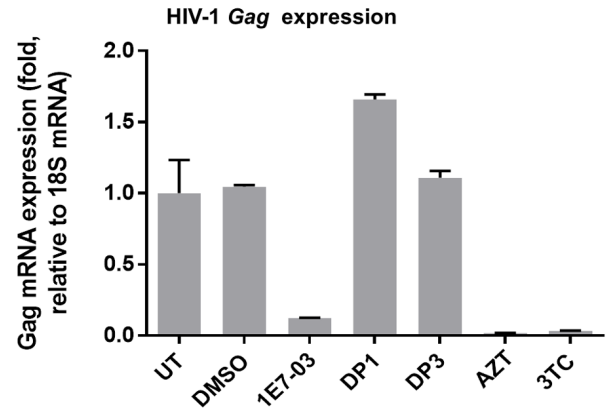

G

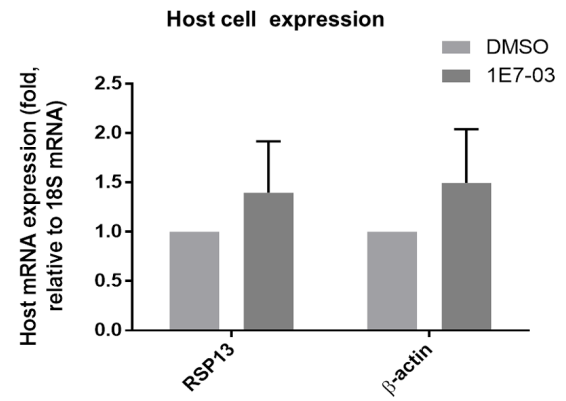

B

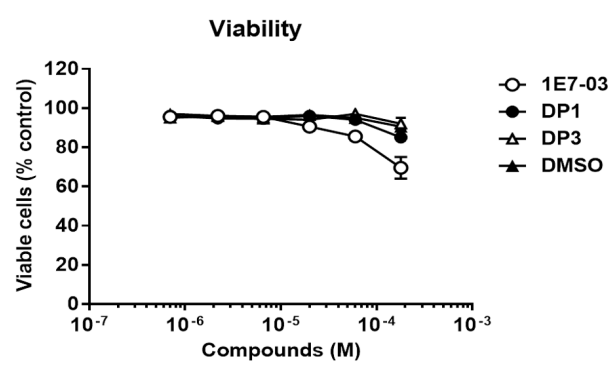

D
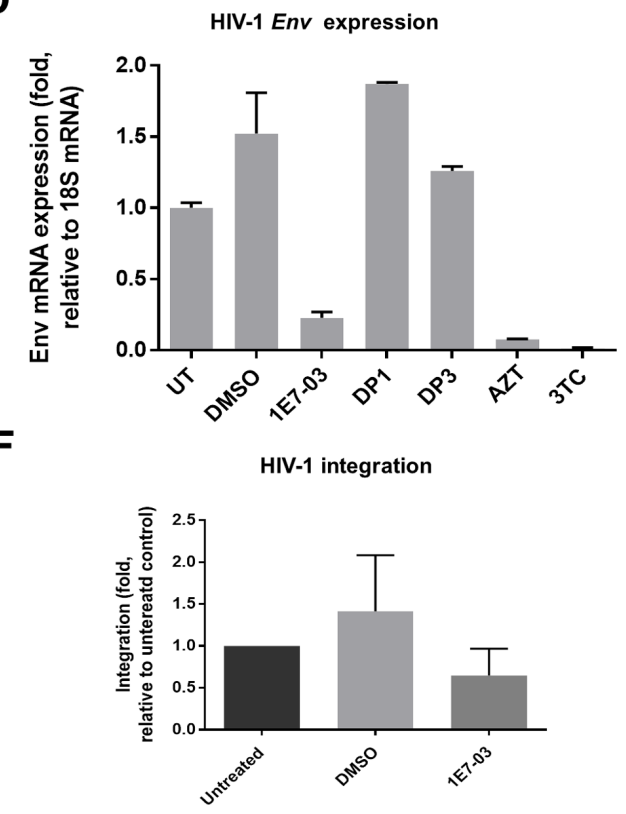

H

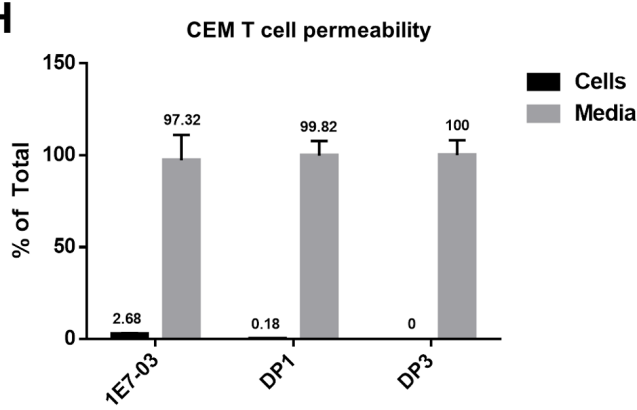

Figure 4: HIV-1 inhibition and cell permeability of 1E7-03, DP1 and DP3. (A) Inhibition of HIV-1 in single round of HIV-1 replication. CEM T cells were infected with HIV-1-LUC-G for $24 \mathrm{hrs}$ and then treated for $24 \mathrm{hrs}$ at $37^{\circ} \mathrm{C}$ with DMSO, 1E7-03, DP1 or DP3. Luciferase activity was then measured.. Percent of luciferase activity is shown. (B) Toxicity of 1E7-03, DP1 and DP3 in CEM T cells. CEM $\mathrm{T}$ cells were treated with the indicated concentrations of the compounds for $24 \mathrm{~h}$ at $37^{\circ} \mathrm{C}$ and cell viability was determined using trypan blue-based assay. (C) The effect of 1E7-03, DP1 and DP3 on luciferase activity. Purified luciferase was incubated with serial dilutions of the compounds or vehicle (DMSO) at room temperature for 10 min. (D-E) Inhibition of HIV-1 env mRNA (D) and HIV-1 gag mRNA (E) expression. RNA was extracted from CEM T cells that were infected with HIV-1-LUC-G for 24 hrs and then treated with DMSO, 10 $\mu \mathrm{M} 1 \mathrm{E} 7-03,10 \mu \mathrm{M}$ DP1, $10 \mu \mathrm{M}$ DP3, $5 \mu \mathrm{M} \mathrm{AZT} \mathrm{or} 5 \mu \mathrm{M}$ 3TC. RNA was reverse transcribed and env and gag mRNA was quantified by real-time PCR using $18 \mathrm{~S}$ mRNA for normalization. $\mathrm{N}=3$ for all panels. The means $\pm \mathrm{SD}$ are shown. (F) The effect of 1E7-03 on HIV-1 integration. CEM T cells were infected with HIV-1-LUC-G and simultaneously treated with $10 \mu \mathrm{M} 1 \mathrm{E} 7-03$ or DMSO. DNA was extracted 6 hrs post infection and analyzed by real-time PCR using Alu and Gag primers for HIV-1 DNA detection and $\beta$-globin gene as a reference. (G) The effect of 1E7-03 on cellular transcription. CEM T cells were treated with $10 \mu \mathrm{M} 1 \mathrm{E} 7-03$ and expression of RSP13 and $\beta$-actin was quantified by real-time RT-PCR using 18S mRNA for normalization. (H) Cell permeability of 1E7-03, DP1 and DP3. Compounds were added to the CEM T cells and incubated for 24 hrs. Amount in the media and intracellular accumulation of compounds was quantified by LC/FT-MS. 


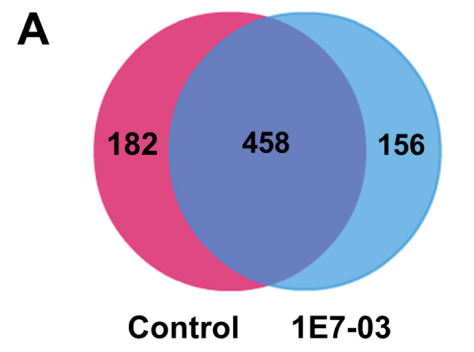

B
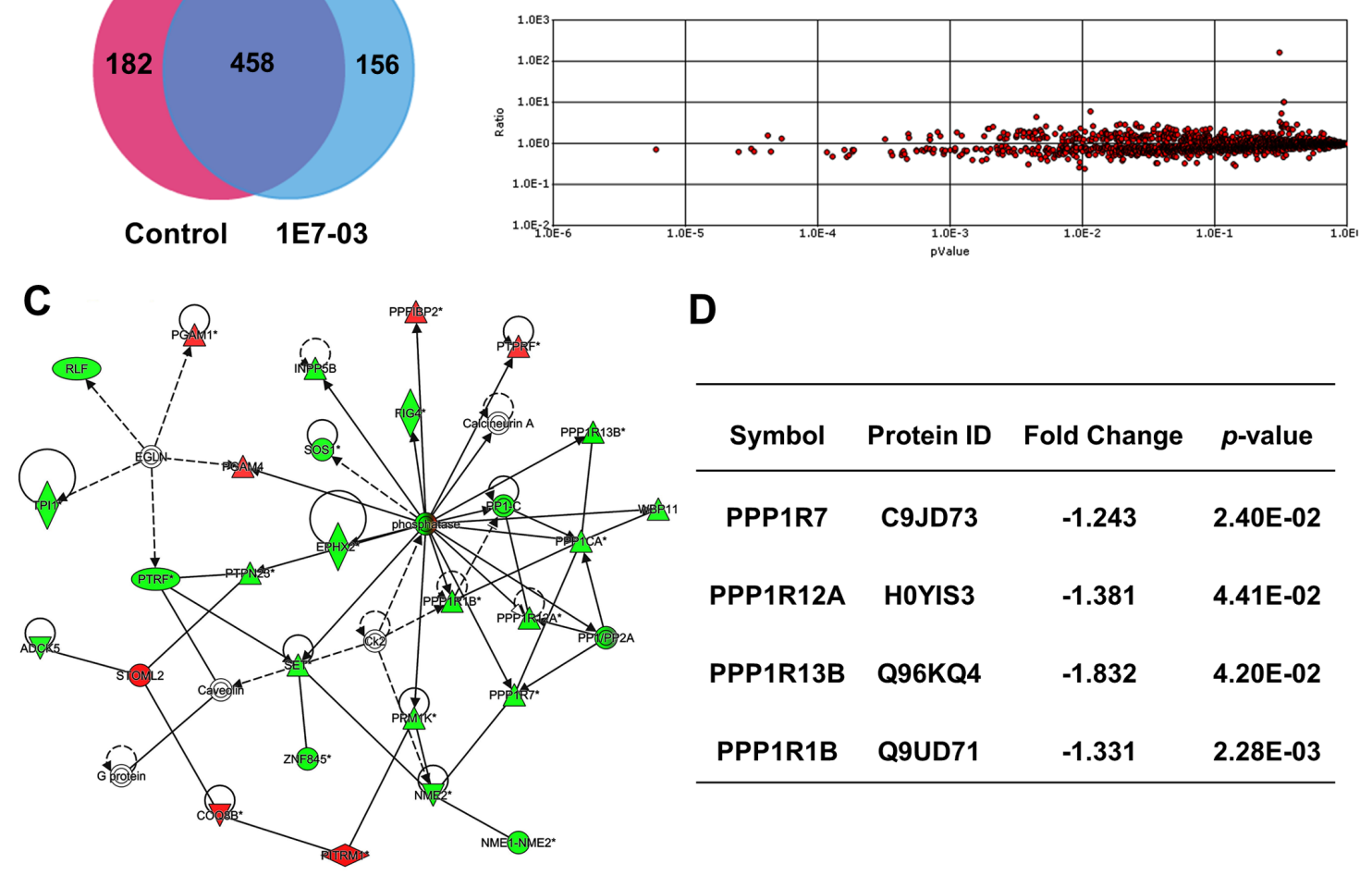

E I EГG L TQГNГL JVГN L R

\begin{tabular}{|c|c|c|c|c|c|c|c|c|c|c|}
\hline & $\left(\mathrm{NH}_{3}+\right) \cdot \mathrm{I}>$ & $\ll \mathrm{G}$ & G> & $\ll Q$ & Q>. & $N>$ & $<v$ & $<\mathrm{N}$ & & $<R$ \\
\hline$b(+1)$ & 114.09135 & 243.13395 & 300.15542 & 413.23949 & 541.29807 & 655.34100 & 768.42507 & 867.49349 & 981.53642 & 1094.62049 \\
\hline$b^{*}(+1)$ & 97.06480 & 226.10740 & 283.12887 & 396.21294 & 524.27152 & 638.31445 & 751.39852 & 850.46694 & 964.50987 & 1077.59394 \\
\hline$b^{\circ}(+1)$ & 96.08078 & 225.12338 & 282.14485 & 395.22892 & 523.28750 & 637.33043 & 750.41450 & 849.48292 & 963.52585 & 1076.60992 \\
\hline$y(+1)$ & 1155.64810 & 1026.60550 & 969.58403 & 856.49996 & 728.44138 & 614.39845 & 501.31438 & 402.24596 & 288.20303 & 175.11896 \\
\hline$y^{*}(+1)$ & 1138.62155 & 1009.57895 & 952.55748 & 839.47341 & 711.41483 & 597.37190 & 484.28783 & 385.21941 & 271.17648 & 158.09241 \\
\hline
\end{tabular}

F

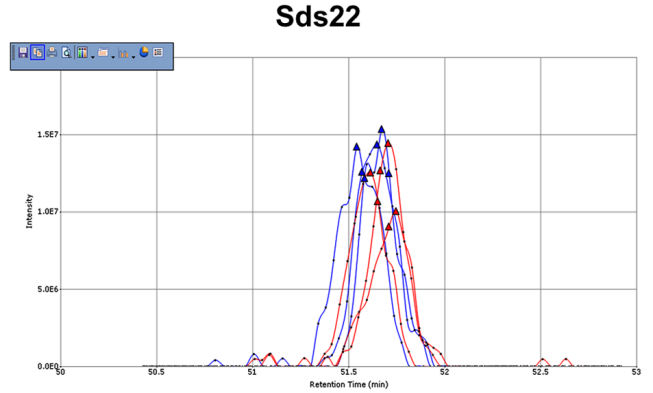

Ratio $=0.804 p$-value $=0.024$
D

\begin{tabular}{cccc}
\hline Symbol & Protein ID & Fold Change & $p$-value \\
\hline PPP1R7 & C9JD73 & -1.243 & $2.40 \mathrm{E}-02$ \\
PPP1R12A & HOYIS3 & -1.381 & $4.41 \mathrm{E}-02$ \\
PPP1R13B & Q96KQ4 & -1.832 & $4.20 \mathrm{E}-02$ \\
PPP1R1B & Q9UD71 & -1.331 & $2.28 \mathrm{E}-03$ \\
\hline
\end{tabular}


free cell culture media, which could be partly attributed to the presence of albumin in the media. Over 90\% 1E703 remained intact in cell culture media after $48 \mathrm{hrs}$ of incubation. Moreover, the 1E7-03 incubated for $24 \mathrm{hrs}$ in media and then added to HIV-1 infected cells showed the same level of HIV-1 inhibition as the freshly prepared 1E7-03, indicating that 1E7-03 was directly responsible for the anti-HIV-1 activities observed in the cultured cells. While the stability of some compounds is $\mathrm{pH}$-dependent, we did not detect any effect of $\mathrm{pH}$ on 1E7-03 degradation pattern tested in buffers with $\mathrm{pH}$ 4-10 (data not shown).

To understand whether DPs retained the ability to target PP1 and inhibit HIV-1, we analyzed their PP1binding affinities and their biological activities. Both DP1 and DP3 bound efficiently to PP1 in vitro $\left(\mathrm{K}_{\mathrm{D}} \sim 4\right.$ $\mu \mathrm{M})$, with a slightly higher affinity than $1 \mathrm{E} 7-03\left(\mathrm{~K}_{\mathrm{D}}=6.2\right.$ $\mu \mathrm{M})$. The affinity of PP1-binding RVxF motif containing peptide $\mathrm{pRb}$-Tat $\left(\mathrm{K}_{\mathrm{D}}=0.16 \mu \mathrm{M}\right)$ was significantly higher

\section{A}

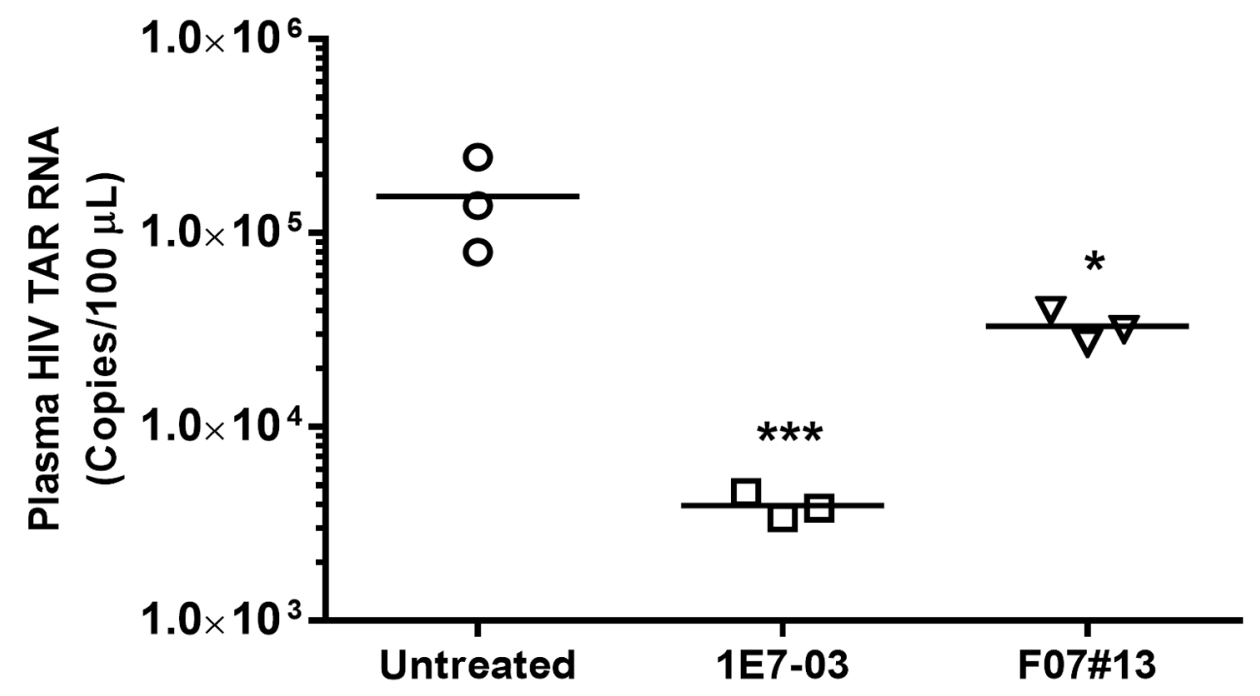

B

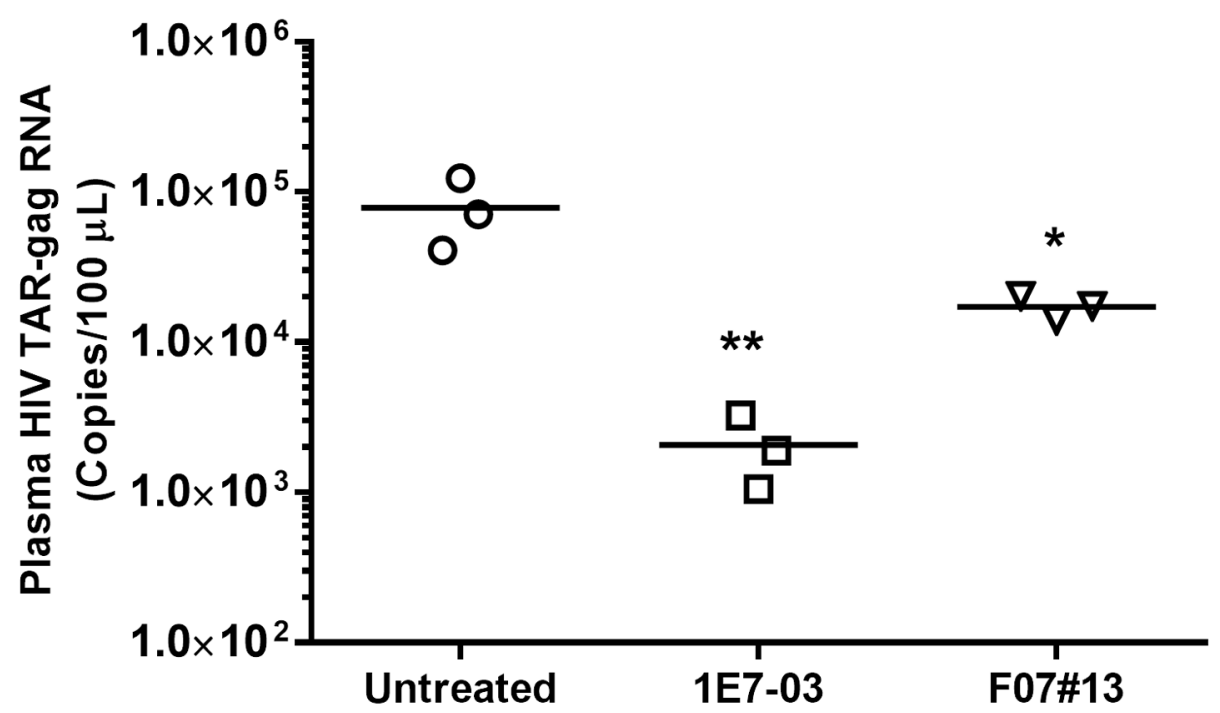

Figure 6: Antiviral efficacy of 1E7-03 in HIV-1 89. 6-infected NSG mice. Mice were treated with 3 mg/kg of 1E7-03 or 1.5 mg/

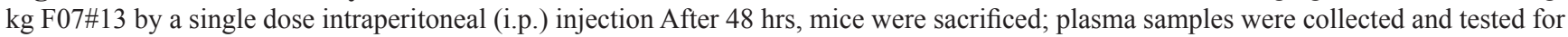
levels of HIV-1 TAR RNA (A) and HIV-1 TAR-gag RNA (B). For quantitative analysis of HIV-1 RNA, total RNA was isolated from blood specimens, treated with RNase-free DNase I and reverse transcribed. Real-time PCR reactions were carried out in triplicates. Each data point represents the blood from a single animal. For all figures, ${ }^{*} p<0.05,{ }^{*} p<0.01,{ }^{* * *} p<0.001$, using unpaired $t$ test. 
A

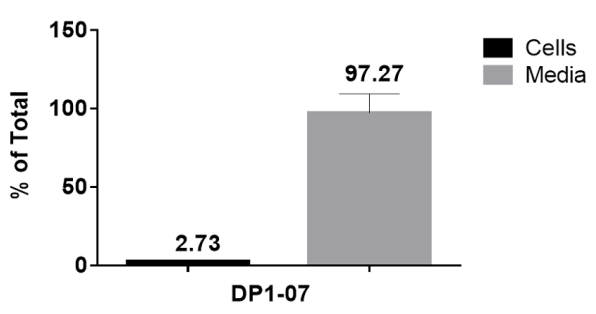

C<smiles>COc1ccc(/C=C2\CCCc3c2nc2ccccc2c3C(=O)OC(C)C(=O)OC(C)(C)C)cc1OC</smiles>

DP1-07

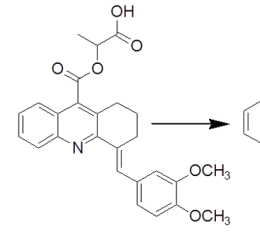

DP1-07P1

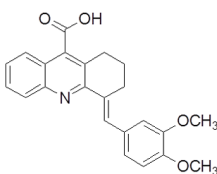

DP1-07P2
B

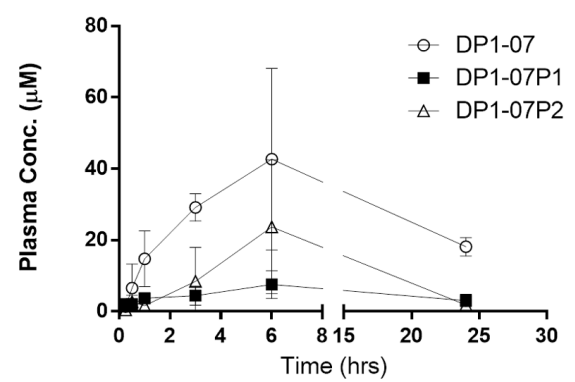

D

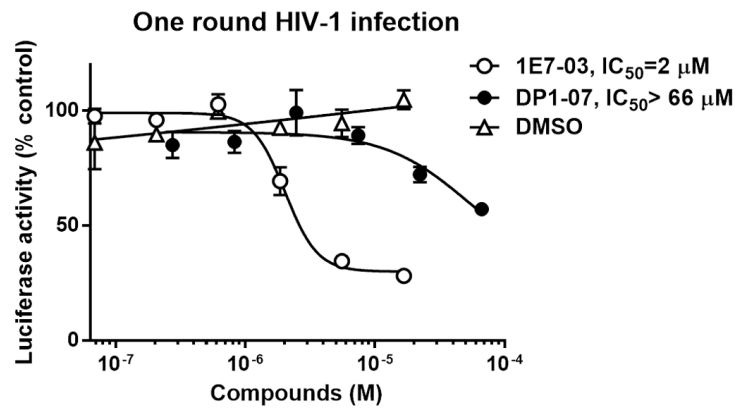

$\mathbf{E}$

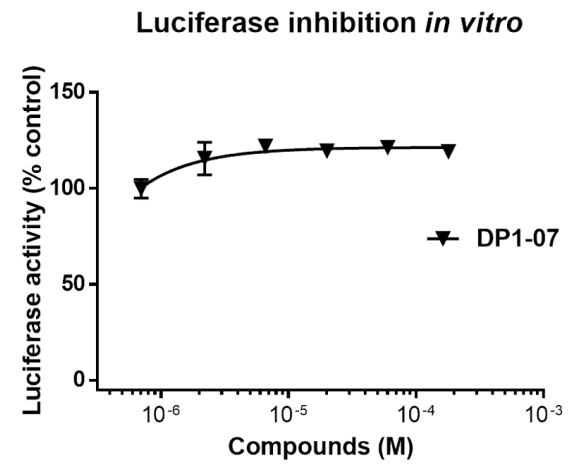

G

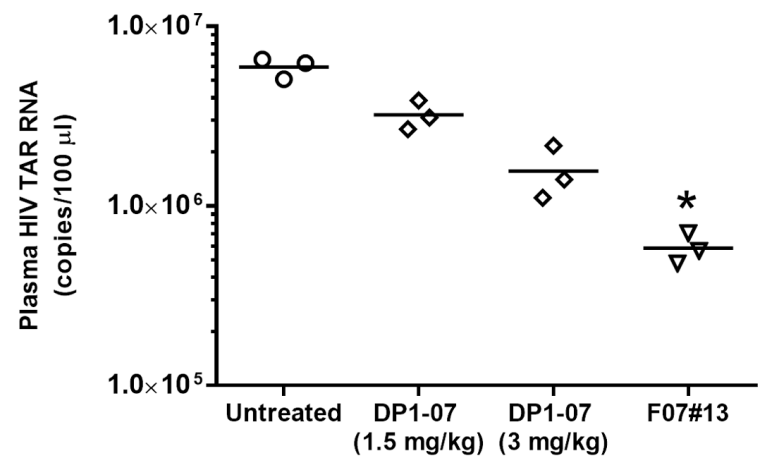

$\mathbf{F}$

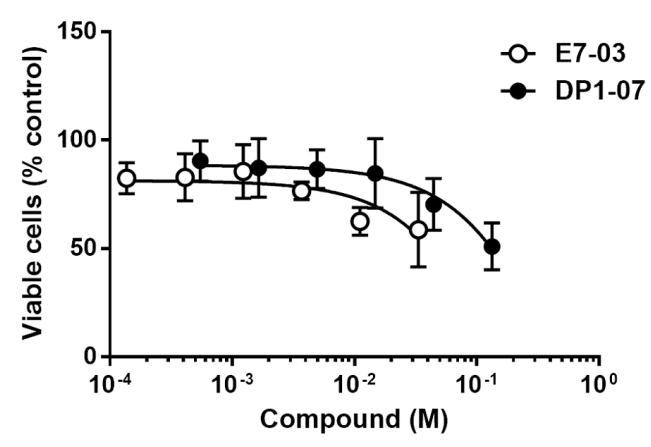

Figure 7: Cellular permeability, pharmacokinetic, and HIV-1 inhibition of the DP1 analog (DP1-07). (A) Amount in the media and intracellular accumulation of DP1-07 after 24 hrs of treatment of CEM T cells. Analysis was performed by LC/FT-MS. (B) Pharmacokinetic of DP1-07 in mice. Mice were injected i.p. either with $100 \mathrm{mg} / \mathrm{kg}$ of DP1-07. The concentrations of DP1-07 and its major DPs in the plasma were quantified by LC/FT-MS. Three mice were used for each time point. The means \pm SD are shown. (C) Scheme of DP1-07 degradation to two products DP1-07P1 and DP1-07P2. (D) HIV-1 inhibition of DP1-07 in single round of HIV-1 replication. CEM T cells were infected with HIV-1-LUC-G. Percent of luciferase activity is shown. (E) The effect of DP1-07 on luciferase activity. Purified luciferase was incubated with serial dilutions of DP1-07 or vehicle (DMSO) under room temperature for $10 \mathrm{~min}$. (F) Toxicity of DP1-07 in CEM T cells. Cells were treated with calcein-AM for $30 \mathrm{~min}$ and calcein fluorescence was measured at $485 \mathrm{~nm}$ excitation and $515 \mathrm{~nm}$ emission. (G) Antiviral efficacy of DP1-07 in HIV-1 89.6-infected NSG mice. Mice were treated with $3 \mathrm{mg} / \mathrm{kg}$ and $1.5 \mathrm{mg} / \mathrm{kg}$ of DP1-07 by a single dose i.p. injection. After $48 \mathrm{hrs,} \mathrm{mice} \mathrm{were} \mathrm{sacrificed} \mathrm{and} \mathrm{plasma} \mathrm{samples} \mathrm{were} \mathrm{tested} \mathrm{for} \mathrm{levels} \mathrm{of} \mathrm{HIV-1} \mathrm{TAR} \mathrm{RNA.} \mathrm{Each} \mathrm{data}$ point represents the blood from a single animal. ${ }^{*} p<0.05$ using unpaired t test. 


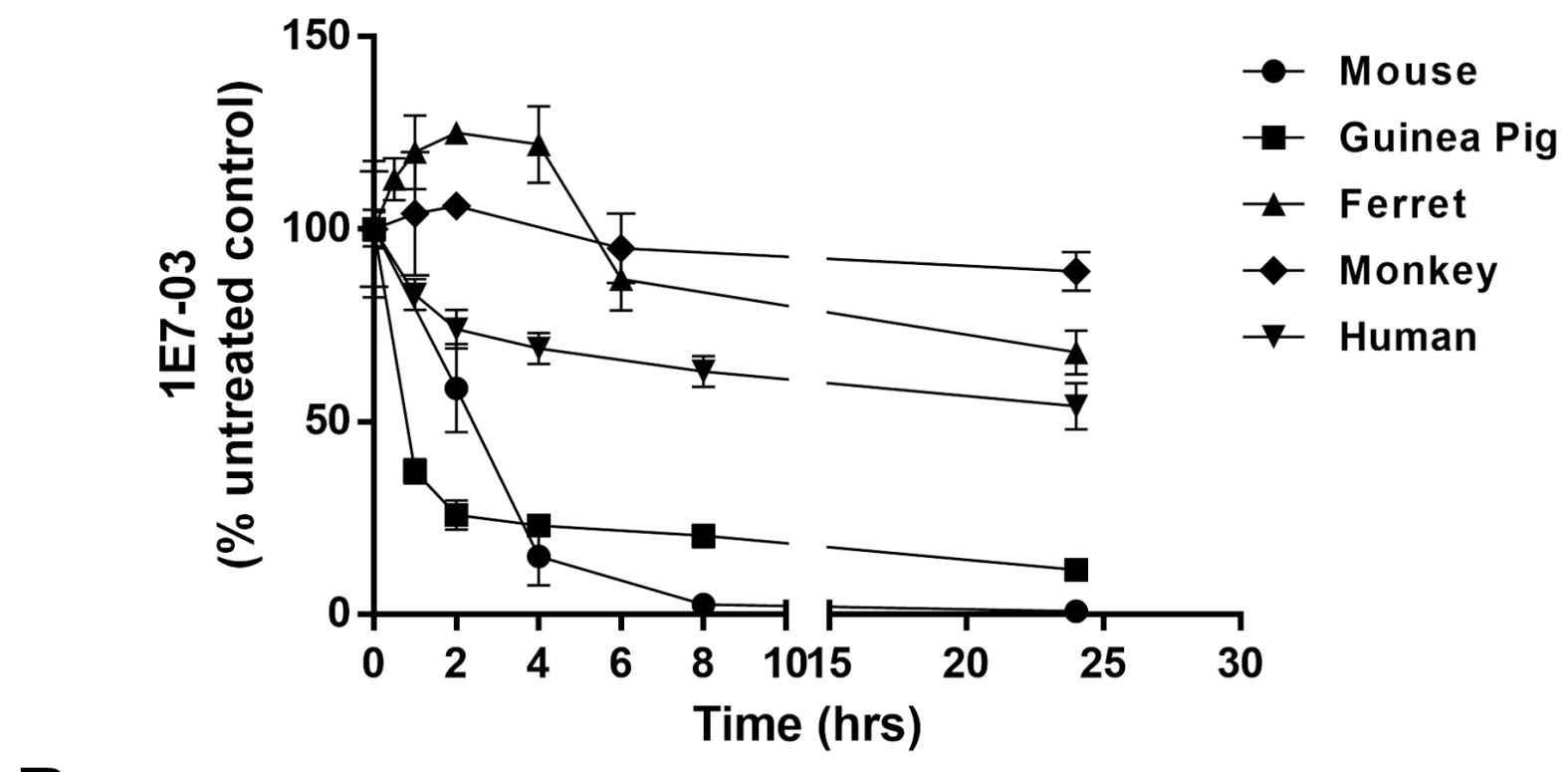

\section{Liver microsomes from human and mouse}

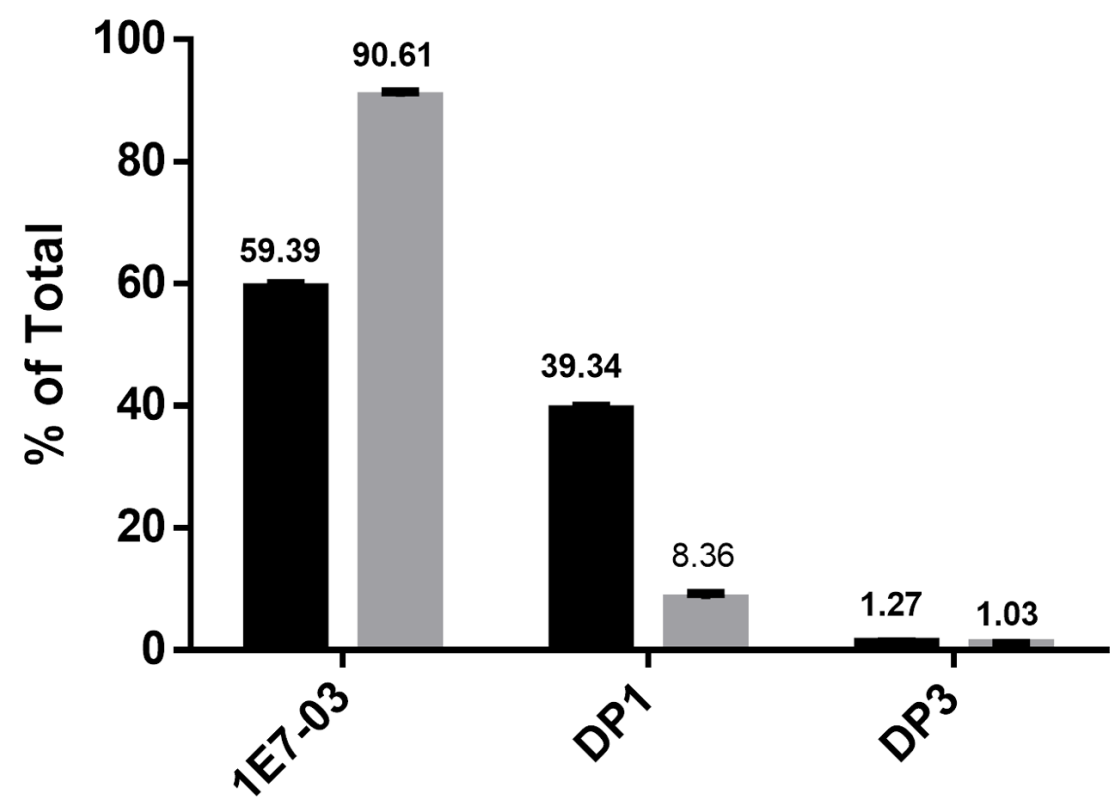

Figure 8: Stability of 1E7-03 in plasma and liver microsomes from different species. (A) Stability of 1E7-03 in plasma from mouse, guinea pig, ferret, monkey and human. 1E7-03 dissolved in DMSO (10 mM stock solution) was mixed with plasma to the final concentration of $10 \mu \mathrm{M}$ and incubated at $37^{\circ} \mathrm{C}$. Samples were collected at different time points for up to $24 \mathrm{hrs}$ and analyzed by LC/FT-MS. (B) Stability of 1E7-03 in liver microsomes from mouse and human. 1E7-03 dissolved in DMSO (10 mM stock solution) was mixed with liver microsomes to the final concentration of $10 \mu \mathrm{M}$ and incubated at $37^{\circ} \mathrm{C}$ for $1 \mathrm{hr}$. Samples were processed and analyzed by LC/FT-MS. All experiments were run parallel in triplicates. 
than the small compounds affinity likely because of an extended binding site in addition to the $\mathrm{RVxF}$ binding motif. Unfortunately, our numerous attempts to cocrystallize PP1 with 1E7-03, DP1 or pRb-Tat were not successful (Wolfgang Peti and Sergei Nekhai, unpublished observations). Thus another approach was needed to elucidate the interaction of 1E7-03 and its DPs with PP1. We performed a competition assay of 1E7-03, DP1 and DP3 with pRb-Tat measured by surface plasmon resonance which showed DP1 being the best in vitro competitor. It reduced the binding of $\mathrm{pRb}$-Tat to PP1 by 10 -fold compared to only about a 2-2.5 -fold reduction by 1E703 and DP3. Thus, a future compound based on the DP1structure may have a strong potential as a PP1-targeting molecule. Unfortunately, DP1 was not efficient as a HIV1 inhibitor. Moreover, its inhibition of HIV-1-LUC-G could be partly attributed by its inhibition of luciferase. This could explain why DP1 did not inhibit expression of HIV-1 env and gag mRNA at a $10 \mu \mathrm{M}$ concentration. The apparent reason for the reduced activity of DP1 was its 10-fold reduced cellular permeability compared to 1E7-03. Therefore, the reduced intracellular concentration of DP1 may explain its reduced antiviral activity.

Our previous studies showed that HIV-1 Tat interacts with PP1 and translocates it to the nucleus [7]. The PP1-targeting HIV-1 inhibitor 1E7-03 binds to PP1 and disrupts the Tat-mediated translocation of PP1 into the nucleus in cultured cells. By targeting PP1, we also developed SMAPP1, an activator of the latent HIV-1 provirus [16]. CDK9 Ser90 has been reported to be phosphorylated by CDK2, which induces HIV1 transcription [21, 22]. We showed SMAPP1 could increase Ser90 phosphorylation of CDK9 by reducing the dephosphorylation activity of PP1 or indirectly activating CDK2 to induce HIV-1 transcription. The protein expression analysis in $\mathrm{T}$ cells showed that SMAPP1 upregulates the PP1-regulatory subunit, Sds22, which is an evolutionarily conserved ancient interactor of PP1 that along with Inhibitor-3 forms a complex with PP1 and helps translocate it to the nucleus [16]. In the current study, label free quantitative proteomics analysis of 1E703 in CEM T cells showed that the expression of Sds22 is downregulated by 1E7-03 treatment during HIV-1 infection, suggesting that expression of Sds22 may change the cellular distribution of PP1 and potentially deregulate translocation of PP1 between cytoplasm and nucleus thus impacting PP1 availability for Tat recruitment and CDK9 dephosphorylation.

NSG mouse model is a useful platform for the preclinical evaluation of antiviral efficacy of HIV-1 targeting therapeutics. This mouse model allows for the establishment of systemic HIV infection and plasma viremia after the initial HIV infection by multiple routes [23]. The successful HIV-1 inhibition by 1E7-03 in humanized mice clearly demonstrates the antiviral potency of this novel PP1-targeting small molecule. A single dose of 1E7-03 injected i.p. at $3 \mathrm{mg} / \mathrm{kg}$ reduced plasma HIV TAR RNA and TAR-gag RNA over 40fold and 39-fold, respectively. These inhibitory effects exceed the effect of F07\#13 (about 5-fold reduction at $1.5 \mathrm{mg} / \mathrm{kg}$ dose), an $\mathrm{HIV}-1$ transcription inhibitor that targets an interface between a CDK and cyclin needed for Tat activated transcription [13]. F07\#13 also suppresses HIV-1 by about 7-fold in the humanized $\mathrm{Rag} 2^{-/-} \mathrm{\gamma c}^{-/-}$mice at $4 \mathrm{mg} / \mathrm{kg}$ [13].

To improve cellular permeability of DP1, we synthesized its analog, DP1-07. This analog demonstrated a cellular permeability similar to 1E7-03, and improved PK properties compared to 1E7-03. Despite that, DP1-07 did not show efficient HIV-1 inhibition $\left(\mathrm{IC}_{50}>66 \mu \mathrm{M}\right)$ in the cellular assay. in vivo, DP1-07 only reduced HIV TAR RNA by 3.8 -fold at $3 \mathrm{mg} / \mathrm{kg}$ in humanized mice, which was about 10-times less efficient than 1E7-03. The lack of improvement of HIV-1 inhibition by DP1-07 over DP1 may be due to the inability of DP1-07 to penetrate to the nucleus or the requirement of the full side chain of 1E7-03 for its anti-HIV activity.

Compounds with certain functional groups including amides, esters, lactams, sulfonamides, tend to undergo hydrolysis by plasma or liver enzymes, exhibiting rapid clearance, short half-lives and consequently poor in vivo activity $[17,19]$. Thus, we tested stability of 1E7-03 in plasma obtained from different species, including human, monkey, ferret and guinea pig. 1E7-03 was stable in human, monkey and ferret plasma and unstable in guinea pig plasma. This could be due to high expression levels of esterases and amidases in rodents [18]. We also tested the stability of 1E7-03 in liver microsomes from human and mouse. 1E7-03 was less stable in liver microsomes from humans than mice.

In summary, 1E7-03 represents the first example of a PP1-targeting small molecule that significantly inhibits HIV-1 in humanized mice. Taking into account the metabolic stability of 1E7-03 in plasma and liver microsomes, further structural modification or optimized drug delivery to improve stability in the liver is pivotal for future testing in non-human primate animal models.

\section{MATERIALS AND METHODS}

\section{Chemicals and reagents}

1E7-03 (purity above 98\%) was synthesized by Enamine (Kiev, Ukraine) as previously described [3]. Acetonitrile and water containing $0.1 \%$ formic acid (FA) were Optima LC/MS grade (Fisher Scientific, Fair Lawn, NJ). High-purity nitrogen $(99.9 \%)$ was purchased from Roberts Oxygen Co, Inc. (Rockville, MD). Other reagents were of analytical grade. Dimethyl sulphoxide (DMSO), acetone, hydrochloric acid and sodium hydroxide were from Fisher Scientific (Fair Lawn, NJ). Phosphate buffered saline ( $\mathrm{pH}$ 7.4) was from Life Technologies (Grand 
Island, NY). Sodium acetate ( $\mathrm{pH}$ 5.2) was from Quality Biological (Gaithersburg, MD).

\section{Cells and media}

CD4 $+\mathrm{T}$ cells $(\mathrm{CEM})$ were purchased from the American Type Culture Collection (Manassas, VA). The CEM cells were cultured in RPMI medium (Invitrogen) containing $10 \%$ FBS and 1\% antibiotic solution (penicillin and streptomycin).

\section{Pharmacokinetic analysis in mice}

The animal facilities and protocols were approved by Howard University Institutional Animal Care and Use Committee (IACUC). All experimental procedures were in accordance with the NIH Guidelines for the Care and Use of Laboratory Animals. BALB/cJ male mice (8 weeks old, 25-30 g) were purchased from Jackson Laboratory (Bar Harbor, ME, USA) and housed under pathogen-free conditions in HEPA-filtered cages and kept on a $12 \mathrm{~h}$ light/ dark cycle. Compounds were administered to mice via intraperitoneal (i.p.) injection with maximum achievable doses of $30 \mathrm{mg} / \mathrm{kg}$ 1E7-03 (100 $\mu \mathrm{l}$ injection of $8 \mathrm{mM} 1 \mathrm{E} 7-$ 03 in $80 \%$ DMSO $/ 20 \%$ saline) and $100 \mathrm{mg} / \mathrm{kg}$ DP $1-07$ (100 $\mu \mathrm{l}$ injection of $100 \mathrm{mM}$ DP1-07 in 40\% propylene glycol/10\% DMSO/50\% saline). Blood samples were collected at different time points (15 min, $30 \mathrm{~min}, 1 \mathrm{hr}, 3$ $\mathrm{hr}, 6 \mathrm{hrs}$ and $24 \mathrm{hrs}$ ) for each group ( $\mathrm{n}=3$ mice per group). For each sample, $20 \mu \mathrm{l}$ of plasma was mixed with $80 \mu \mathrm{l}$ cold acetone, and centrifuged at 13,000 rpm for $5 \mathrm{~min}$. The supernatant was transferred to a clean test tube and dried in a SpeedVac concentrator. The residue was re-constituted in $50 \mu \mathrm{l}$ of acetonitrile for LC-MS analysis. Calibration curves were prepared by spiking 1E7-03, DP1, DP3 and DP1-07 into the drug-free mouse plasma and subjected to similar sample extraction procedures. The plasma concentration-time profile of each analyte was constructed and pharmacokinetic parameters were determined by noncompartmental method using Phoenix WinNonlin Version 5.3 (Pharsight Corporation, Mountain View, CA).

\section{Generation of NSG-BLT mice and treatment of 1E7-03 and DP1-07}

NOD.Cg-Prkdcscid Il2rgtm $1 \mathrm{Wj} 1 / \mathrm{SzJ}$ (NSG) mice initially purchased from Jackson Laboratories were bred and maintained in the Animal Core Facility at George Mason University (Manassas, VA). NSG mice were generated by i.p. injection of cryopreserved human CD34+ hematopoietic stem progenitor cells (HSPC) (500,000 cells per mouse) isolated from the autologous fetal liver [23]. Anesthetized mice were inoculated by direct injection 16 weeks after implantation with $50 \mu \mathrm{l}$ of HIV-1 89.6 (1,000 TCID50) or RPMI 1640 medium (mock infection). Upon reconstitution and presence of virus in the plasma (typically 4-8 weeks), the animals were treated with a single i.p. of 1E7-03 (3 mg/kg), DP1-07 (1.5 mg/ $\mathrm{kg}$ or $3 \mathrm{mg} / \mathrm{kg})$ or F07\#13 (1.5 mg/kg) [13]. Blood was collected by tail vein after $48 \mathrm{hrs}$ and transferred into microcentrifuge tubes containing $330 \mathrm{mM}$ EDTA. Each data point represents the blood from a single animal. Plasma was removed after low-speed centrifugation for 5 $\mathrm{min}$ at room temperature and stored at $-80^{\circ} \mathrm{C}$. Viral RNA was extracted from plasma using the QIAamp Viral RNA Mini Kit (Qiagen). For quantitative analysis of HIV-1 RNA, total RNA was isolated from blood specimens of HIV-1-infected humanized mice. RNA was isolated using Trizol Reagent (Invitrogen, Carlsbad, CA) according to the manufacturer's protocol. A total of $1.0 \mu \mathrm{g}$ of RNA was treated with $0.25 \mathrm{mg} / \mathrm{ml}$ DNase I RNase-free (Roche, Mannheim, Germany) for $60 \mathrm{~min}$ in the presence of $5 \mathrm{mM}$ $\mathrm{MgCl}_{2}$, followed by heat inactivation at $65^{\circ} \mathrm{C}$ for $15 \mathrm{~min}$. A 200-250 ng aliquot of total RNA was used to generate cDNA with the GoScript Reverse Transcription System (Promega, Madison, WI) using TAR-specific reverse primer TAR+59R: 5'- CAACAGACGGGCACACACTAC $-3^{\prime}$. Subsequent quantitative real-time PCR analysis was performed with $2 \mu \mathrm{l}$ of undiluted RT reaction mixes. The iQ Supermix (Bio-Rad, Hercules, CA) was used with the primers specific for (1) HIV-1 TAR: TARfll-F: 5'-GGTCTCTCTGGTTAGACCAGATCTG-3' and TAR+59R as above; (2) HIV-1 TAR-gag: Gag 1625R: 5'GCTGGTAGGGCTATACATTCTTAC -3' and TAR+59R as above. Real-time PCR reactions were carried out in triplicate.

\section{Synthesis of DP1, DP3 and DP1-07}

Synthesis of DP3 began with a Pfitzinger reaction between isatin (1) and cyclopentanone resulting in the formation of tricyclic acid 2 (see schematics in Supplementary Figure 1A). Reaction of the latter with veratraldehyde furnished the desired product, DP3. Chemical synthesis of DP1 is described in Supplementary Figure 1B. It began with a base-mediated coupling of DP3 with secondary bromide 4 resulting in the formation of diester 5. Chemoselective deprotection of the $t$-butyl ester resulted in the formation of DP1. Synthesis of DP107 is described in Supplementary Figure 1C. Briefly, it began with a Pfitzinger reaction between isatin and cyclohexanone resulting in forming of tricyclic acid (intermediate product 6). Reaction of the product 6 with veratraldehyde resulted in formation of intermediate product 7 . The intermediate 7 reacted with secondary bromide 4 resulted in the formation of desired product DP1-07.

\section{LC/FT-MS analysis}

A $10 \mu \mathrm{l}$ aliquots from each sample were loaded to a LC-20AD nano HPLC system (Shimadzu Corporation, 
Columbia, MD, USA) coupled to LTQ XL Orbitrap mass spectrometer (Thermo Fisher Scientific) with the installed Xcalibur software (version 2.0.7, Thermo Fisher Scientific). Liquid chromatography was carried out on an in-house made nano-HPLC column (Polymicro Technologies Inc., Phoenix, AZ, USA) packed with

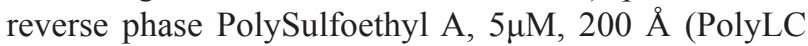
Inc., Columbia, MD, USA). Mobile phase A was $0.1 \%$ formic acid in water and mobile phase B - $0.1 \%$ formic acid in acetonitrile. The elution was performed at a flow rate of $600 \mathrm{nl} / \mathrm{min}$ over $40 \mathrm{~min}$ using a multisegment linear gradient of mobile phase B as follows: 0-6.02 min, 1\% B; 6.02-6.11 min, 1-2\% B; 6.11-20 min, 2-80\% B; 20-25 min, 80\% B; 25-30 min, 80-85\% B; 30-31 min, 80-2\% B; 31-40 min, 2\% B (v/v). The Orbitrap was operated under data-dependent acquisition mode. The spray voltage, capillary temperature and capillary voltage were set to $2.0 \mathrm{kV}, 200{ }^{\circ} \mathrm{C}$, and $39.5 \mathrm{~V}$, respectively. Full-scan mass spectra were acquired in Orbitrap over $150-1500 \mathrm{~m} / \mathrm{z}$ with a resolution of 30000 , followed by $\mathrm{MS}^{\mathrm{n}}$ scans by CID activation mode. The precursor ions were fragmented with collision energy of 18 with activation Q of 0.25 and an activation time of $30 \mathrm{~ms}$. Dynamic exclusion was enabled with a repeat count of 2 , a repeat duration of $15 \mathrm{~s}$, exclusion duration of $20 \mathrm{~s}$, an exclusion list size of 50 . The mass spectrometer was also operated in NL scan of $m / z$ 18.01, 45.05, 71.03 and 72.02 and MRM mode. The MRM transitions were controlled by a segmented program in order to short the scan cycle and increase sensitivity.

\section{LC/FT-MS instrument validation}

1E7-03, DP1 and DP3 were dissolved in DMSO $(10 \mathrm{mM})$ and then diluted in acetonitrile to prepare stock solutions $(30 \mu \mathrm{M})$. The 1E7-03, DP1 and DP3 stock solutions were mixed and then serially diluted to produce calibration standard solutions $(10,5,1,0.5,0.1,0.05$, and $0.01 \mu \mathrm{M}$ for each compound). The analysis was carried out in triplicates. The peak area versus concentration data were analyzed by least squares linear regression analysis. The intra- and inter-day precisions were established by analyzing drug solution at $1 \mu \mathrm{M}$ concentration, and six individual analyses were conducted on the same day and on three consecutive days. Accuracy was determined by analyzing a known concentration of drug solution spiked with samples from mouse serum, cell culture media and buffer $(\mathrm{pH}=7.0)$ incubations in triplicate and then determining the percent recovery. The limit of detection (LOD) and limit of quantification (LOQ) were estimated at a signal-to-noise of 3:1 and 10:1, respectively, by injecting a series of diluted solutions with known concentrations.

\section{Analysis of 1E7-03 degradation in plasma}

1E7-03 dissolved in DMSO (10 $\mathrm{mM}$ stock solution) was mixed with mouse plasma (Sigma-
Aldrich), guinea pig plasma (Sigma-Aldrich), ferret plasma (BioreclamationIVT), monkey plasma (courtesy of Binhua Ling, PhD, Tulane University) and human plasma (collected from heathy volunteer by the Center for Sickle Cell Disease at Howard University) to the final concentration of $10 \mu \mathrm{M}$ and incubated at $37^{\circ} \mathrm{C}$. Aliquots were collected at different time points for up to $24 \mathrm{hrs}$. The resulting sample $(60 \mu \mathrm{l})$ was mixed with $240 \mu \mathrm{l}$ of cold acetone, vortexed for $2 \mathrm{~min}$, kept at $-20^{\circ} \mathrm{C}$ for 30 min, and then the precipitated protein was removed by centrifugation at $13,000 \times \mathrm{g}$ for $5 \mathrm{~min}$. The supernatant was transferred to a clean test tube and evaporated to dryness using a SpeedVac concentrator. The residue reconstituted in $60 \mu \mathrm{l}$ of acetonitrile for LC/FT-MS analysis. All experiments were run parallel in triplicates.

\section{Analysis of 1E7-03 degradation in plasma and liver microsomes}

The metabolic stability of 1E7-03 was also investigated using a pool of human and mouse liver microsomes (HMS9PL, MSS9PL, Thermo Scientific) following manufacturer's instructions. In brief, incubations were conducted at $37 \pm 1^{\circ} \mathrm{C}$ in mixtures containing $5 \mu \mathrm{l}$ of human or mouse liver microsomes $(20 \mathrm{mg} / \mathrm{ml}), 183 \mu \mathrm{l}$ of potassium phosphate buffer ( $\mathrm{pH} 7.4,100 \mathrm{mM})$ and 2 $\mu \mathrm{l}$ of 1E7-03 (10 mM sock solution of 1E7-03 in DMSO was diluted into $1 \mathrm{mM}$ by PBS). The mixture was preincubated for $5 \mathrm{~min}$, then initiated the reactions with the addition of $10 \mu \mathrm{l} 20 \mathrm{mM}$ NADPH (Sigma Aldrich). The reactions were terminated after $1 \mathrm{hr}$ incubation by adding $800 \mu \mathrm{l}$ cold acetone. The mixture was kept at $4^{\circ} \mathrm{C}$ for $30 \mathrm{~min}$, and the precipitated protein was removed by centrifugation $\left(13,000 \mathrm{~g}\right.$ for $10 \mathrm{~min}$ at $\left.4^{\circ} \mathrm{C}\right)$. A $250 \mu \mathrm{l}$ aliquot of supernatant was transferred to a clean test tube and evaporated to dryness using a SpeedVac concentrator. The residue was reconstituted in $50 \mu \mathrm{l}$ of acetonitrile with $0.1 \%$ FA for LC/FT-MS analysis.

\section{Stability of 1E7-03 in cell culture media and PBS}

CEM T cells were seeded in 24-well plates $(200,000$ cells/well). On the next day cells were treated with $10 \mu \mathrm{M}$ 1E7-03. Media (100 $\mu \mathrm{l})$ was collected at different time points during $48 \mathrm{hrs}$ and total protein was precipitated by $400 \mu \mathrm{l}$ of cold acetone and centrifuged at $13,000 \times \mathrm{g}$ for $5 \mathrm{~min}$. The supernatant was collected and evaporated to dryness using a SpeedVac concentrator. The dry pellet was reconstituted in $100 \mu \mathrm{l}$ of acetonitrile for LC/FT-MS analysis. In addition, 1E7-03 $(10 \mu \mathrm{M})$ was incubated at $37^{\circ} \mathrm{C}$ in serum-free media and complete media without cell treatment. Media of $100 \mu \mathrm{l}$ was collected after 24 hrs of incubation. The stabilities of 1E7-03 $(10 \mu \mathrm{M})$ at phosphate buffered saline (PBS) and PBS with the addition of $10 \%$ bovine serum albumin were also investigated at $37^{\circ} \mathrm{C}$ incubation. Samples $(100 \mu \mathrm{l})$ were collected 
at different time points up to $24 \mathrm{hrs}$. All samples were prepared by the same above-mentioned procedure for $\mathrm{LC} /$ FT-MS analysis.

\section{Effect of pH on 1E7-03 degradation}

1E7-03 (10 mM) stability at various $\mathrm{pH}$ was tested at $37^{\circ} \mathrm{C}$ in sodium acetate-acetic acid buffer $(\mathrm{pH}=4)$, $\mathrm{NaH}_{2} \mathrm{PO}_{4} / \mathrm{Na}_{2} \mathrm{HPO}_{4}$ buffer $(\mathrm{pH}=7)$ and $\mathrm{NaHCO}_{3} / \mathrm{NaOH}$ buffer $(\mathrm{pH}=10)$. Samples $(100 \mathrm{ml})$ were collected at different time points up to $48 \mathrm{hrs}$, and evaporated to dryness using a SpeedVac concentrator immediately. The pellets resolved in $100 \mu \mathrm{l}$ of acetonitrile, vortexed for $2 \mathrm{~min}$, then centrifuged at $13,000 \times \mathrm{g}$ for $5 \mathrm{~min}$. The supernatant was transferred to a clean tube for LC-MS analysis.

\section{PP1 expression}

PP1 was purified as previously described [3]. BL21 (DE3) Escherichia coli cells (Invitrogen, Carlsbad, CA, USA) were -transformed with a vector expressing human PP1 $\alpha$ (residues 7-300) and pGR07, which expresses GroEL/GroED chaperones (both gifts from Dr Mathieu Bollen and Monique Beullens, KU Leuven, Belgium). The cells were grown in media supplemented with $1 \mathrm{mM} \mathrm{MnCl} 2$ at $30^{\circ} \mathrm{C}$ to an $\mathrm{A}_{600}=0.5$. Arabinose $(2 \mathrm{~g}$ per $\mathrm{L})$ was added to induce expression of the GroEL/GroES chaperones. When $A_{600}=1$ was reached, the cells were transferred to $10^{\circ} \mathrm{C}$ and PP1 expression was induced with $0.1 \mathrm{mM}$ Isopropyl $\beta$-D-1thiogalactopyranoside for $20 \mathrm{hrs}$. Harvested cells were lysed using sonication in a solution containing in $50 \mathrm{mM}$ Tris- $\mathrm{HCl}$ (pH 8.0), $5 \mathrm{mM}$ imidazole, $700 \mathrm{mM} \mathrm{NaCl}, 1 \mathrm{mM} \mathrm{MnCl} 2$, $0.1 \%$ Triton X-100 (v/v) and protease inhibitors. His-tagged PP1 was purified using a Ni-NTA IMAC column (Qiagen, Valencia, CA, USA). Purified PP1 was dialyzed and stored at $-70^{\circ} \mathrm{C}$ in $50 \mathrm{mM}$ Tris- $\mathrm{HCl}(\mathrm{pH} 8.0), 5 \mathrm{mM}$ imidazole, $700 \mathrm{mM} \mathrm{NaCl}$ and $1 \mathrm{mM} \mathrm{MnCl}_{2}$. PP1 activity was then assayed as previously described [4].

\section{Surface plasmon resonance (SPR)}

The SPR measurements were conducted on Biacore T200 instrument (GE Healthcare, Piscataway, NJ) at $25^{\circ} \mathrm{C}$. Recombinant PP1 was immobilized on a CM5 chip by amine coupling (GE Healthcare). PP1 (200 nM) was captured on flow cell 2 in $10 \mathrm{mM}$ acetate buffer, $\mathrm{pH}$ 5.0, supplemented with $2 \mathrm{mM} \mathrm{MnCl}$. The average amount of PP1 immobilized on the surface was 3160 RU. Flow cell 1 was used as a reference surface to subtract background signal. Also injections of the buffer alone were used to provide double reference subtraction. To measure the direct binding of small molecules to PP1, the two flow cells of the sensor chip were primed with running buffer (0.01 M HEPES pH 7.4, $0.15 \mathrm{M} \mathrm{NaCl}, 0.005 \% \mathrm{v} / \mathrm{v}$ Surfactant P20, 1\% DMSO and $2 \mathrm{mM} \mathrm{MnCl}_{2}$ ). For binding and kinetics experiments, all compounds were diluted in the running buffer, at $40 \mu \mathrm{M}, 20 \mu \mathrm{M}, 10 \mu \mathrm{M}, 5 \mu \mathrm{M}, 2.5$ $\mu \mathrm{M}, 1.25 \mu \mathrm{M}$ and $0 \mu \mathrm{M}$ and then passed over the two flow cells at a flow rate of $100 \mu \mathrm{l} / \mathrm{min}$ for $60 \mathrm{sec}$. The number of response units was recorded after the subtraction of the reference flow cell's value (Fc2-1). Two repetitions were performed for each injection. Data were analyzed using the BiaEvaluation software of Biacore with a 1:1 binding model. For the competition assay, the hybrid peptide consisting of parts of $\mathrm{pRb}$ and Tat protein sequences, HIPR(pS)PYKFPSSPLRKKCCFHCQVCFITK (with a single serine amino acid phosphorylated) was used at 10 $\mathrm{nM}, 25 \mathrm{nM}, 50 \mathrm{nM}, 75 \mathrm{nM}$ and $100 \mathrm{nM}$. All the small molecular weight compounds were used at $1 \mu \mathrm{M}$.

\section{Cell viability assays}

CEM T cells were cultured in 96 -well plates at $37^{\circ} \mathrm{C}$ and incubated with the indicated compound concentrations for 24 hrs. Cell viability was determined using trypan bluebased assay. The cells were supplemented with $0.2 \%$ trypan blue, transferred to a plastic disposable counting chamber and counted on a TC10 Automatic Cell Counter (Bio-Rad).

To assess cytotoxicity with calcein, media was removed and the cells washed with PBS in order to remove serum esterase activity that may cause an increase in fluorescence through the hydrolysis of calcein-AM. Cells were then supplemented with $0.2 \mu \mathrm{M}$ calceinAM (Molecular Probes, Invitrogen) for $10 \mathrm{~min}$ at $37^{\circ} \mathrm{C}$. Fluorescence was measured using the luminescence spectrometer described above implementing $495 \mathrm{~nm}$ excitation and $515 \mathrm{~nm}$ emission filters.

\section{Luciferase assays}

CEM $T$ cells were infected with VSVGpseudotyped pNL4-3.Luc.R-E-virus (HIV-1-LUC-G) prepared as previously described [22] and cultured in 96-well white plates $\left(1.25 \times 10^{6}\right.$ cells $/ \mathrm{ml}, 100 \mu \mathrm{l} /$ well $)$ at $37^{\circ} \mathrm{C}$ and $5 \% \mathrm{CO}_{2}$. The cells were treated with serial dilutions of the compounds or vehicle (DMSO) and incubated overnight. At $24 \mathrm{hrs}$ post infection, $100 \mu \mathrm{l}$ of reconstituted luciferase buffer (Luclite Kit, Perkin Elmer) was added to each well, incubated for $10 \mathrm{~min}$ and luminescence was measured using Glo-Max Microplate Multimode reader (Promega).

QuantiLum Recombinant Luciferase (20 ng/ml in PBS) was added into 96-well plate $(100 \mu \mathrm{l} /$ well $)$ and incubated with serial dilutions of the compounds or vehicle (DMSO) under room temperature for $10 \mathrm{~min} .100$ $\mu l$ of reconstituted luciferase buffer (Luclite Kit, Perkin Elmer) was added to each well, incubated for another $10 \mathrm{~min}$ and luminescence was measured using Glo-Max Microplate Multimode reader (Promega).

\section{Quantitative RT PCR}

For quantitative analysis of HIV-1 RNA, CEM T cells were infected with HIV-1-LUC-G virus. Cells were treated 
with $10 \mu \mathrm{M}$ 1E7-03, $10 \mu \mathrm{M}$ DP1, $10 \mu \mathrm{M}$ DP3, $5 \mu \mathrm{M}$ AZT or $5 \mu \mathrm{M} 3 \mathrm{TC}$ and control cells were untreated or treated with DMSO. Total RNA was isolated using Trizol Reagent (Invitrogen, Carlsbad, CA) according to the manufacturer's protocol. Total RNA (100 ng) was reverse transcribed to cDNA using Superscript ${ }^{\mathrm{TM}}$ RT-PCR kit (Invitrogen, Carlsbad, CA). Hexamers and oligo-dT were used as primers. For real-time PCR analysis, cDNA was amplified using Roche LightCycler 480 (Roche Diagnostics) and SYBR Green1 Master mix (Roche Diagnostics). PCR was run for 45 cycles and each cycle included denaturation at $95^{\circ} \mathrm{C}$ for 10 seconds, annealing at $60^{\circ} \mathrm{C}$ for 10 seconds, and extension at $72^{\circ} \mathrm{C}$ for 10 seconds. Quantification of env and gag was carried using 18S RNA as a normalization standard. Quantification of housekeeping genes, $\beta$-actin and RSP13 was carried relative to $18 \mathrm{~S}$ RNA. Mean Cp values were determined and $\Delta \Delta \mathrm{Ct}$ method was used to calculate relative expression levels. Unpaired $t$-test was used to test statistical significance.

The following primer sequences were used: $e n v$, forward - CCTTTGAGCCAATTCCCATACATT, reverseGACGTTTGGTCCTGTTCCATTGAACGT; gag, forward- ATAATCCACCTATCCCAGTAGGAGAAAT, reverse- TITGGTCCITGTCITATGTCCAGAATGC; $\beta$-actin, forward- CTCCCAAAGTGCTGGGATTA, reverse-CAAAGGCGAGGCTCTGTG; RSP13, forward- AGATGTGGGAAGGTTGGTGG, reverseTTTCTCGAGCAGTACCTATCTGG; and 18SrRNA, forward- GCTGTTGCTACATCGACCTTT, reverseCTCCAGGTTTTGCAACCAGT.

To assay HIV-1 integration, CEM T cells were infected with HIV-1-LUC-G virus and treated with 10 $\mu \mathrm{M}$ 1E7-03 or DMSO. Total DNA was extracted from cells using lysis buffer $(10 \mathrm{mM}$ Tris- $\mathrm{HCl} \mathrm{pH} 8.0,10$ $\mathrm{mM}$ EDTA, $5 \mathrm{mM} \mathrm{NaCl}, 200 \mu \mathrm{g} / \mathrm{ml}$ proteinase $\mathrm{K})$. The cells were lysed for 20-30 min at room temperature and proteinase $\mathrm{K}$ was inactivated by heating to $95^{\circ} \mathrm{C}$ for $5 \mathrm{~min}$. For the real-time PCR analysis, $100 \mathrm{ng}$ DNA was amplified using Roche Light Cycler 480 (Roche Diagnostics) and SYBR Green1 Master mix (Roche Diagnostics). PCR was carried with initial preincubation for $5 \mathrm{~min}$ at $45^{\circ} \mathrm{C}$ and then for 3 in at $95^{\circ} \mathrm{C}$ followed by 45 cycles of denaturation at $95^{\circ} \mathrm{C}$ for $15 \mathrm{sec}$, annealing and extension at $60^{\circ} \mathrm{C}$ for $45 \mathrm{sec}$, and final extension at $72^{\circ} \mathrm{C}$ for $10 \mathrm{sec}$. Integrated HIV1 DNA was amplified using the following primers: Alu forward 5'-GCCTCAATAAAGCTTGCCTTGA-3', and Gag reverse 5'-GCTCTCGCACCCATCTCTCTCC-3'.

\section{Cellular permeability assay}

CEM T cells were seeded in 6 -well plates $(0.5$ $\mathrm{x} 10^{6}$ cells $/ \mathrm{ml}$ ) and treated by $10 \mu \mathrm{M}$ of the indicated compounds. Two samples were generated for each compound (in triplicates) obtained from cellular lysate and media sample. Cell culture media samples $(100 \mu \mathrm{l})$ were collected from each well after $24 \mathrm{hrs}$ of incubation and total protein was precipitated by the addition of $400 \mu \mathrm{l}$ cold acetone. Protein pellets were washed three times with PBS to remove any compound that had not permeated into the cells. To obtain cell lysates, the cells were suspended in $300 \mu \mathrm{l}$ cold whole cell lysis buffer (50 mM Tris-HCl, pH 7.5, $0.5 \mathrm{M} \mathrm{NaCl}, 1 \% \mathrm{NP}-40,0.1 \%$ SDS) and sonicated. A $100 \mu \mathrm{l}$ aliquot of the cell lysate was combined with $400 \mu \mathrm{l}$ cold acetone to precipitate proteins. All samples were centrifuged at $13,000 \times \mathrm{g}$ for $5 \mathrm{~min}$. Supernatants containing compounds and their metabolites were collected and evaporated to dryness on SpeedVac concentrator. The dry pellet was reconstituted in $50 \mu \mathrm{l}$ acetonitrile for LC/FT-MS analysis.

\section{Label free quantitative proteomics analysis}

CEM T cells were infected with VSVG-pseudotyped pNL4-3.Luc.R-E-virus (HIV-1-LUC-G) and cultured in $100 \mathrm{~mm}$ culture plates $\left(1.25 \times 10^{6}\right.$ cells $\left./ \mathrm{ml}\right)$ containing 10 $\mathrm{ml}$ of supplemented RPMI media at $37^{\circ} \mathrm{C}$ and $5 \% \mathrm{CO}_{2}$. The cells were treated with $10 \mu \mathrm{M}$ of $1 \mathrm{E} 7-03$ or vehicle (DMSO) and incubated overnight. Cells were collected and washed three times with PBS. To obtain cell lysates, the cells were suspended in $1 \mathrm{ml}$ cold whole cell lysis buffer (50 mM Tris-HCl, pH 7.5, 0.5 M NaCl, 1\% NP$40,0.1 \%$ SDS) with protease and phosphatase inhibitors (P044-1ML, Sigma Aldrich). The cytosolic protein fraction was isolated by centrifugation at $13,000 \mathrm{xg}$ for $30 \mathrm{~min}$ at $4{ }^{\circ} \mathrm{C}$ to remove cellular debris. An aliquot of cell lysate normalized to cell number was mixed with 4-fold volume cold acetone to precipitate proteins. All samples were centrifuged at $13,000 \times \mathrm{g}$ for $5 \mathrm{~min}$. Protein precipitations were collected and evaporated to dryness on SpeedVac concentrator. The pellet was resuspended in sodium phosphate buffer $(\mathrm{pH} 8.0)$, reduced in 10 $\mathrm{mM}$ dithiothreitol $\left(1 \mathrm{hr}\right.$ at $\left.60^{\circ} \mathrm{C}\right)$, alkylated with $30 \mathrm{mM}$ iodoacetamide (20 min, room temperature in the dark) and digested with $10 \mu \mathrm{g}$ trypsin (Promega) at $37^{\circ} \mathrm{C}$ on orbital shaker.

Tryptic peptides were purified by Pierce ${ }^{\mathrm{TM}}$ Graphite Spin Columns following manufacturer's instructions, resuspended in water with $0.1 \%$ formic acid (v/v) and analyzed by an LTQ Orbitrap XL mass spectrometer (Thermo Fisher Scientific) coupled to a Prominence Nano LC (Shimadzu) using the Xcalibur version 2.7.0 (Thermo Scientific). A total of $10 \mu \mathrm{L}$ of sample was loaded and washed for $6 \mathrm{~min}$ on a C18-packed precolumn $(1 \mathrm{~cm} \times 150$ $\mu \mathrm{m}, 5 \mu \mathrm{m}, 200 \AA$, Michrom Bioresources, Auburn, CA) with a solvent of $A: B=99: 1$ ( $A, 0.1 \%$ formic acid aqueous solution; $\mathrm{B}, 0.1 \%$ formic acid acetonitrile solution) at a constant flow of $12 \mu \mathrm{l} / \mathrm{min}$. Peptides were transferred onward to a C18-packed analytical column $(25 \mathrm{~cm} \times 150$ $\mu \mathrm{m}, 5 \mu \mathrm{m}, 200 \AA$, Michrom Bioresources, Auburn, CA) and separated with a linear gradient of 6-55 $\mathrm{min}, 2-40 \%$ B, 55-62 $\mathrm{min}, 40-80 \% \mathrm{~B}, 62-70 \mathrm{~min}, 80 \% \mathrm{~B}(\mathrm{v} / \mathrm{v})$ at the flow rate of $600 \mathrm{nl} / \mathrm{min}$. The mass spectrometer performed 
a full MS scan ( $m / z$ 300-2000) at a resolution of 30000. The spray voltage, capillary temperature and capillary voltage were set to $2.0 \mathrm{kV}, 200{ }^{\circ} \mathrm{C}$, and $39.5 \mathrm{~V}$, respectively. The three most intense ions were selected for fragmentation using collision-induced dissociation (CID) in the LTQ (normalized collision energy of 35 , parent mass selection window of $2.5 \mathrm{Da}$, activation time of $30 \mathrm{~ms}$, and minimum signal threshold for MS/MS scans set to 500 counts). Charge state rejection (charge state 1 was rejected) as well as dynamic exclusion (repeat counts, 2; repeat duration, 10 $\mathrm{s}$; exclusion duration, $10 \mathrm{~s}$ ) was enabled.

LC-MS/MS raw data were searched by Proteome Discoverer 1.4 using Sequest search engine (Thermo Fisher Scientific), against the Uniprot Human database $(6 / 10 / 2016,135431$ sequences $)$ at a false discovery cut off $\leq 1 \%$. A maximum of two missed cleavage sites was allowed. The mass tolerance for the precursor ion was set on $10 \mathrm{ppm}$ and for the fragment on $0.1 \mathrm{Da}$. Oxidation of methionine and phosphorylation of serine, threonine and tyrosine were enabled as dynamic modifications, while carbamidometylation of cysteine was set as fixed modification. The label-free quantification of peptides eluting between 10 and 80 min was performed with SIEVE 2.1 software (Thermo Scientific). Briefly, the chromatographic peaks detected by Orbitrap were aligned and the peptides peaks were detected with a minimum signal intensity of $1 \times 10^{5}$; quantitative frames were determined based on $\mathrm{m} / \mathrm{z}$ (width: $10 \mathrm{ppm}$ ) and retention time (width: $2.5 \mathrm{~min}$ ). Statistical filters were set to assess the quality of the data. A $p$-value cutoff of 0.05 was used to define the altered proteins, and the CV raw MS intensities of the triplicates had to be within 30\%. This helped minimize the effect of run-to-run variability. A list of differentially-expressed proteins and their gene/protein ID numbers was uploaded to the Ingenuity Pathway Analysis (IPA, Ingenuity Systems, CA) software for a Core analysis to investigate the protein function and biological networks.

\section{Statistical analysis}

All graphs were prepared using GraphPad prism 6 software. Data are presented as mean \pm SD or standard error of the mean (SEM) as indicated in the figure legends. Means were compared with Student t tests.

\section{Abbreviations}

HIV-1: human immunodeficiency virus; PP1: protein phosphatase-1; DPs: degradation products; LC/ FT-MS: liquid chromatography/Fourier transform mass spectrometry; SPR: surface plasmon resonance; PK: pharmacokinetic; i.p.: intraperitoneal.

\section{Author contributions}

XL conducted the research, analyzed results, and wrote the manuscript. DK and AK designed and synthesized PP1-targeting small molecules and contributed to the preparation of the manuscript. YSK, TA, NK, MJ, GVM and AI conducted experiments and analyzed results. AÜ participated in the study design and wrote the manuscript. FK and CD performed animal experiments with humanized HIV-1 infected mice. FK also participated in the study design and writing the manuscript. SN takes primary responsibility for the paper. SN designed experiments, analyzed results, and drafted the manuscript.

\section{ACKNOWLEDGMENTS}

We thank Binhua Ling (Tulane University) for the gift of monkey plasma. The authors also thank Dr Mathieu Bollen and Dr Monique Beullens for the gift of PP1 and GroEL/GroES chaperon bacterial expression vectors. We also thank Anton Nekhai for careful and editing of the manuscript. The work was supported by sponsored research finding from NIH to SN (P50HL118006, 1R01HL125005, and 5G12MD007597, AI117970 and U19AI109664), to SN and AÜ (UL1TR000101) and to FK (AI078859, AI078859, and AI043894).

\section{CONFLICTS OF INTEREST}

Patent: Sergei Nekhai, Dmytro Borysovich Kovalskyy "Inhibitors of protein phosphatase-1 and uses thereof" (U.S. application number: 12/424, 243; publication number: US 2009/0264463 A1).

\section{FUNDING}

Funding for this study was from NIH research grants 1P50HL118006, 1R01HL125005, and 5G12MD007597, District of Columbia Developmental Center for AIDS Research grant AI117970 and U19AI109664 (to SN). This project was also supported by grant number UL1TR000101 from National Center for Advancing Translational science (NCATS), a component of National Institutes of Health (NIH) (to SN and AÜ). This work was further supported by National Institutes of Health Grants AI078859, AI078859, and AI043894 (to FK). The content is solely the responsibility of the authors and does not necessarily represent the official view of NHLBI, NIAID, NIMHD, NCATS or NIH.

\section{REFERENCES}

1. Wightman F, Solomon A, Khoury G, Green JA, Gray L, Gorry PR, Ho YS, Saksena NK, Hoy J, Crowe SM, Cameron PU, Lewin SR. Both CD31(+) and CD31(-) naive CD4(+) T cells are persistent HIV type 1-infected reservoirs in individuals receiving antiretroviral therapy. J Infect Dis. 2010; 202: 1738-48. doi: 10.1086/656721.

2. Carter CC, Onafuwa-Nuga A, McNamara LA, Riddell JT, Bixby D, Savona MR, Collins KL. HIV-1 infects multipotent progenitor cells causing cell death and 
establishing latent cellular reservoirs. Nat Med. 2010; 16: 446-51. doi: nm.2109 [pii] 10.1038/nm.2109.

3. Ammosova T, Platonov M, Ivanov A, Kont YS, Kumari N, Kehn-Hall K, Jerebtsova M, Kulkarni AA, Uren A, Kovalskyy D, Nekhai S. 1E7-03, a low MW compound targeting host protein phosphatase-1, inhibits HIV-1 transcription. Br J Pharmacol. 2014; 171: 5059-75. doi: 10.1111/bph.12863.

4. Ammosova T, Platonov M, Yedavalli VR, Obukhov Y, Gordeuk VR, Jeang KT, Kovalskyy D, Nekhai S. Small molecules targeted to a non-catalytic "RVxF" binding site of protein phosphatase-1 inhibit HIV-1. PLoS One. 2012; 7 : e39481. doi: 10.1371/journal.pone.0039481.

5. Ammosova T, Yedavalli VR, Niu X, Jerebtsova M, Van Eynde A, Beullens M, Bollen M, Jeang KT, Nekhai S. Expression of a protein phosphatase 1 inhibitor, cdNIPP1, increases CDK9 threonine 186 phosphorylation and inhibits HIV-1 transcription. J Biol Chem. 2011; 286: 3798-804. doi: 10.1074/jbc.M110.196493.

6. Ammosova T, Jerebtsova M, Beullens M, Voloshin Y, Ray PE, Kumar A, Bollen M, Nekhai S. Nuclear protein phosphatase-1 regulates HIV-1 transcription. J Biol Chem. 2003; 278: 32189-94. doi: 10.1074/jbc.M300521200.

7. Ammosova T, Jerebtsova M, Beullens M, Lesage B, Jackson A, Kashanchi F, Southerland W, Gordeuk VR, Bollen M, Nekhai S. Nuclear targeting of protein phosphatase-1 by HIV-1 Tat protein. J Biol Chem. 2005; 280: 36364-71. doi: 10.1074/jbc.M503673200.

8. Bollen M, Peti W, Ragusa MJ, Beullens M. The extended PP1 toolkit: designed to create specificity. Trends Biochem Sci. 2010; 35: 450-8. doi: S0968-0004(10)00046-0 [pii] 10.1016/j.tibs.2010.03.002.

9. Heroes E, Lesage B, Gornemann J, Beullens M, Van Meervelt L, Bollen M. The PP1 binding code: a molecularlego strategy that governs specificity. FEBS J. 2013; 280: 584-95. doi: 10.1111/j.1742-4658.2012.08547.x.

10. Ilinykh PA, Tigabu B, Ivanov A, Ammosova T, Obukhov Y, Garron T, Kumari N, Kovalskyy D, Platonov MO, Naumchik VS, Freiberg AN, Nekhai S, Bukreyev A. Role of protein phosphatase 1 in dephosphorylation of Ebola virus VP30 protein and its targeting for the inhibition of viral transcription. J Biol Chem. 2014; 289: 22723-38. doi: 10.1074/jbc.M114.575050.

11. Baer A, Shafagati N, Benedict A, Ammosova T, Ivanov A, Hakami RM, Terasaki K, Makino S, Nekhai S, Kehn-Hall K. Protein Phosphatase-1 regulates Rift Valley fever virus replication. Antiviral Res. 2016; 127: 79-89. doi: 10.1016/j. antiviral.2016.01.007.

12. Iordanskiy S, Van Duyne R, Sampey GC, Woodson CM, Fry K, Saifuddin M, Guo J, Wu Y, Romerio F, Kashanchi F. Therapeutic doses of irradiation activate viral transcription and induce apoptosis in HIV-1 infected cells. Virology. 2015; 485: 1-15. doi: 10.1016/j.virol.2015.06.021.

13. Van Duyne R, Guendel I, Jaworski E, Sampey G, Klase Z, Chen H, Zeng C, Kovalskyy D, El Kouni MH, Lepene B,
Patanarut A, Nekhai S, Price DH, et al. Effect of mimetic CDK9 inhibitors on HIV-1-activated transcription. J Mol Biol. 2013; 425: 812-29. doi: 10.1016/j.jmb.2012.12.005.

14. Klebanoff SJ, Mehlin C, Headley CM. Activation of the HIV type 1 long terminal repeat and viral replication by dimethylsulfoxide and related solvents. AIDS Res Hum Retroviruses. 1997; 13: 1221-7.

15. Kumari N, Iordanskiy S, Kovalskyy D, Breuer D, Niu $\mathrm{X}$, Lin X, Xu M, Gavrilenko K, Kashanchi F, Dhawan $\mathrm{S}$, Nekhai S. Phenyl-1-Pyridin-2yl-ethanone-based iron chelators increase IkappaB-alpha expression, modulate CDK2 and CDK9 activities, and inhibit HIV-1 transcription. Antimicrob Agents Chemother. 2014; 58: 6558-71. doi: AAC.02918-14 [pii] 10.1128/AAC.02918-14.

16. Tyagi M, Iordanskiy S, Ammosova T, Kumari N, Smith K, Breuer D, Ilatovskiy AV, Kont YS, Ivanov A, Uren A, Kovalskyy D, Petukhov M, Kashanchi F, et al. Reactivation of latent HIV-1 provirus via targeting protein phosphatase-1. Retrovirology. 2015; 12: 63. doi: 10.1186/s12977-015-0190-4.

17. Konsoula R, Jung M. In vitro plasma stability, permeability and solubility of mercaptoacetamide histone deacetylase inhibitors. Int J Pharm. 2008; 361: 19-25. doi: 10.1016/j. ijpharm.2008.05.001.

18. Bahar FG, Ohura K, Ogihara T, Imai T. Species difference of esterase expression and hydrolase activity in plasma. J Pharm Sci. 2012; 101: 3979-3988. doi: 10.1002/jps.23258.

19. Asha S, Vidyavathi M. Role of human liver microsomes in in vitro metabolism of drugs-a review. Appl Biochem Biotechnol. 2010; 160: 1699-1722. doi: 10.1007/ s12010-009-8689-6.

20. Lin JH, Lu AY. Role of pharmacokinetics and metabolism in drug discovery and development. Pharmacol Rev. 1997; 49: 403-49.

21. Breuer D, Kotelkin A, Ammosova T, Kumari N, Ivanov A, Ilatovskiy AV, Beullens M, Roane PR, Bollen M, Petukhov MG, Kashanchi F, Nekhai S. CDK2 regulates HIV-1 transcription by phosphorylation of CDK9 on serine 90 . Retrovirology. 2012; 9: 94. doi: 10.1186/1742-4690-9-94.

22. Debebe Z, Ammosova T, Breuer D, Lovejoy DB, Kalinowski DS, Kumar K, Jerebtsova M, Ray P, Kashanchi F, Gordeuk VR, Richardson DR, Nekhai S. Iron chelators of the di-2pyridylketone thiosemicarbazone and 2-benzoylpyridine thiosemicarbazone series inhibit HIV-1 transcription: identification of novel cellular targets--iron, cyclindependent kinase (CDK) 2, and CDK9. Mol Pharmacol. 2011; 79: 185-196. doi: 10.1124/mol.110.069062.

23. Stoddart CA, Galkina SA, Joshi P, Kosikova G, Moreno ME, Rivera JM, Sloan B, Reeve AB, Sarafianos SG, Murphey-Corb M, Parniak MA. Oral administration of the nucleoside EFdA (4'-ethynyl-2-fluoro-2'-deoxyadenosine) provides rapid suppression of HIV viremia in humanized mice and favorable pharmacokinetic properties in mice and the rhesus macaque. Antimicrob Agents Chemother. 2015; 59: 4190-4198. doi: 10.1128/AAC.05036-14. 